\title{
Evaluation of Styrene and Dust Exposures and Health Effects during Fiberglass-Reinforced Wind Turbine Blade Manufacturing
}

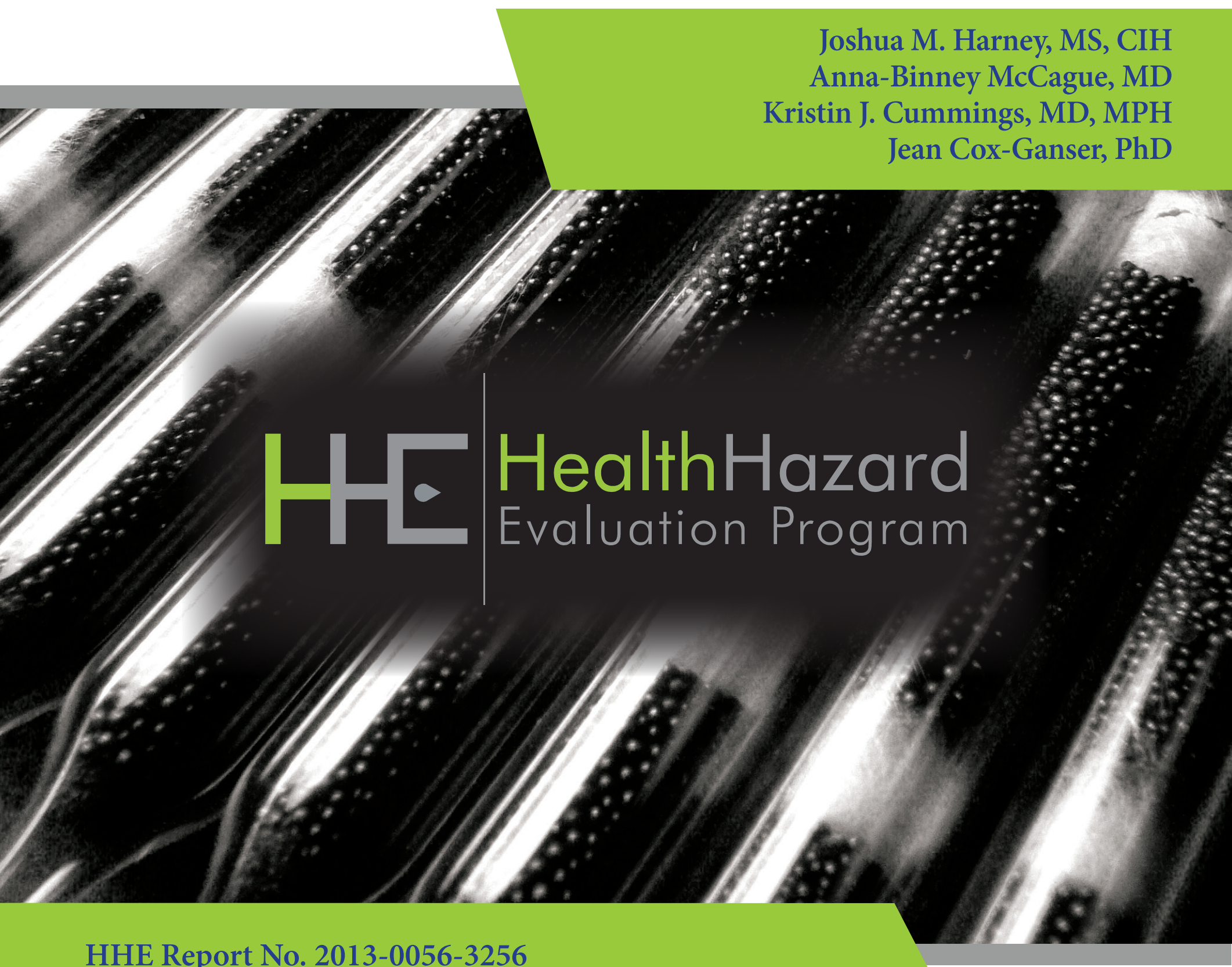

HHE Report No. 2013-0056-3256

August 2016

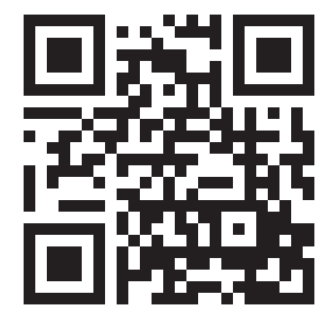

U.S. Department of Health and Human Services Centers for Disease Control and Prevention

National Institute for Occupational Safety and Health

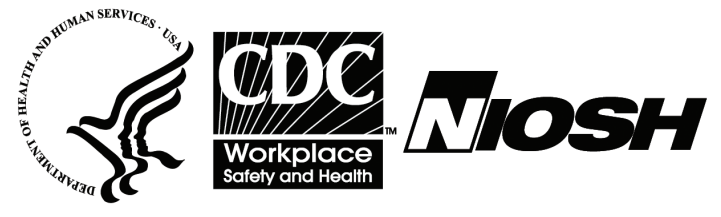




\section{Contents}

Highlights.

Abbreviations ...................................... iii

Introduction ............................................ 1

Methods ............................................... 6

Results .............................................. 17

Discussion ........................................ 33

Conclusions........................................ 40

Recommendations.......................... 40

Appendix A ....................................... 44

Appendix B......................................... 47

Appendix C........................................... 58

References......................................... 61

Acknowledgements........................... 66

The employer is required to post a copy of this report for 30 days at or near the workplace(s) of affected employees. The employer must take steps to ensure that the posted report is not altered, defaced, or covered by other material.

The cover photo is a close-up image of sorbent tubes, which are used by the HHE Program to measure airborne exposures. This photo is an artistic representation that may not be related to this Health Hazard Evaluation. Photo by NIOSH. 


\section{Highlights of this Evaluation}

The Health Hazard Evaluation Program received a request from managers at a wind turbine blade manufacturing plant. They were concerned about employee exposures to styrene and dust.

\section{What We Did}

- We interviewed employees to learn about their health and safety concerns.

- In June 2013, we sampled the air for styrene, dust, and xylene.

- In July 2013, we offered all current employees a health and work history questionnaire, vision tests, breathing tests, and a urine test for styrene exposure.

\section{What We Found}

- Some airborne styrene concentrations in blade cut and trim were above exposure limits.

- Airborne dust concentrations in the departments that do a lot of sanding and grinding were much higher than exposure limits.

- The average amount of styrene getting into employees' bodies was below the recommended limit.

- Color blindness was much more common in employees than in the general population.

- Employees with higher styrene exposure the day of testing had more contrast vision problems.

- Employees with higher long-term exposure to styrene had more chest symptoms and lower lung function problems.

\section{What the Employer Can Do}

- Improve mold designs and the blade closing process to limit the need for work that generates styrene and dust exposures.

- Use sanding and grinding tools with exhaust ventilation shrouds that conform more closely

We assessed employee exposures to styrene and dust and evaluated employees' visual and respiratory health at a fiberglass-reinforced wind turbine blade manufacturer. Urinary styrene metabolites were lower than exposure limits. Employees had more color blindness than expected, and contrast vision problems were related to current and long-term styrene exposure. Employees exposed to higher levels of styrene had more breathing problems than expected. We recommended changes to the blade manufacturing process to reduce styrene exposures. For annual employee medical exams, we recommended vision testing and spirometry. to the shape of the blade surface.

- Ensure that employees use and store personal protective equipment as required, and evaluate 'bystander' employee exposure to styrene in high exposure departments.

- Consider offering color and contrast vision testing as a part of employees' annual health exam.

- Use signs that employees with color and contrast vision deficiencies can see. 
- Begin annual spirometry for all production employees and any office employees who regularly walk through production areas.

\section{What Employees Can Do}

- Hold sanders and grinders flat to the work surface so the dust gets captured by the local exhaust ventilation system.

- Wear respiratory and skin protection as directed by your employer.

- Store respirators so they do not get crushed, misshapen, or contaminated with dust.

- Participate in health screenings and spirometry testing offered by your employer.

- Report new or ongoing symptoms to your personal physician and to the plant nurse. 


\section{Abbreviations}

$\begin{array}{ll}\text { ACGIH® } & \text { American Conference of Governmental Industrial Hygienists } \\ \text { BMI } & \text { Body mass index } \\ \text { CCI } & \text { Color confusion index } \\ \text { CFR } & \text { Code of Federal Regulations } \\ \text { FeNO } & \text { Fraction of exhaled nitric oxide } \\ \text { FEV } & \text { Forced expiratory volume } \\ \text { FVC } & \text { Forced vital capacity } \\ \text { gram } & \text { Gram } \\ \text { mg } & \text { Milligram } \\ \text { mg/m } & \text { Milligrams per cubic meter } \\ \text { mL } & \text { Milliliter } \\ \text { MA } & \text { Mandelic acid } \\ \text { ng/mL } & \text { Nanograms per milliliter } \\ \text { NHANES } & \text { National Health and Nutrition Examination Survey } \\ \text { NIOSH } & \text { National Institute for Occupational Safety and Health } \\ \text { OEL } & \text { Occupational exposure limit } \\ \text { OSHA } & \text { Occupational Safety and Health Administration } \\ \text { PEL } & \text { Permissible exposure limit } \\ \text { PGA } & \text { Phenylglyoxilic acid } \\ \text { PHEMA } & \text { N-Acetyl-S-(phenyl-2-hydroxyethyl-L-cysteine) } \\ \text { ppb } & \text { Parts per billion } \\ \text { ppm } & \text { Parts per million } \\ \text { PPE } & \text { Personal protective equipment } \\ \text { REL } & \text { Recommended exposure limit } \\ \text { TLV® } & \text { Threshold limit value } \\ \text { TWA } & \text { WEEL }\end{array}$


This page left intentionally blank 


\section{Introduction}

The Health Hazard Evaluation Program received a request from managers at a wind turbine blade manufacturer. They were concerned about employee exposures to dust and styrene. Industrial hygiene evaluations at this facility in 2007 and 2008 found dust and styrene exposures that exceeded occupational exposure limits (OELs). Since that time, the company has sought to reduce employee exposures by product substitution and improvements to ventilation, employee work practices, and personal protective equipment (PPE) use. Following these changes, we made visits in March, June, and July 2013 to evaluate exposures and health effects. We sent the company and employee representatives interim letters with exposure monitoring results in September 2013 and with medical results in April 2014.

\section{Process Description}

At this two-building facility, the main structural parts of the blades are fabricated onsite. The basic construction of the blades includes a balsa wood reinforced fiberglass outer shell supported by interior braces. The outer blade shell is made of two halves, each molded separately and then sealed together with adhesive and fiberglass patches. Building 1 housed the following operations: blade molding, mold closure, bushing winding (during our first visit only), and kitting. Building 2 housed the following operations: blade cut and trim, finishing and assembly, web molding, web cut and trim, and bushing winding (during our second and third visits). During our visits, facility staffing ranged from 300-500 employees, operations were continuous, and most blades produced were approximately 42 meters long.

\section{Blade Molding}

Building 1 housed four blade production rooms, each containing at least one pair of blade molds. Mold preparers cleaned the molds so that the blades' outer surfaces would be as smooth as possible. A gel coater then sprayed a styrene-containing pigmented resin into the mold. During gel coating, an interlock between the gel coat sprayer and the building's singlepass general ventilation system increased fresh air supply by $20 \%$. The gel coat hardened, becoming the outer surface of the blade. Blade assemblers then manually layered textile fiberglass sheets and balsa wood into the mold. Once these materials were in place, the blade assemblers covered each mold with a thin plastic sheet that was vacuum sealed to the surface of the blade's interior. With the assistance of this vacuum pressure, resin was pumped through the blade materials to saturate them and bond them to the gel coat upon curing. Employees wore bump caps and safety glasses. Some employees also voluntarily wore disposable MicroMAX® coveralls or shirts for protection against dust. When gel coat was sprayed, and for 30 minutes following completion of spraying, employees in the department also wore an elastomeric half-mask respirator with organic vapor cartridges, or a more protective respirator. Those employees spraying gel coat or operating the gel coat spraying machines also wore disposable MicroMAX ${ }^{\circledR}$ coveralls, extended cuff disposable green nitrile gloves, and their choice of a full facepiece elastomeric respirator or hooded powered air purifying respirator, both with organic vapor cartridges. 


\section{Mold Closure}

Once each blade half cured, employees inspected it and repaired any small imperfections in the blade's interior surface. Employees made repairs by sanding or grinding the surface using powered hand tools equipped with local exhaust ventilation and then vacuuming the blade's interior surface. If necessary they also manually rolled resin on repair spots using a 4" paint roller. Teams of two to four employees then pumped styrene-containing glue onto all the blade surfaces that touched the other blade half and internal bracing. Employees brought the blade's interior bracing, called a "web" or "webbing" from Building 2 into the blade molding room and then a crane operator placed it into the lower half of the blade. A hydraulic mold closer then lifted the second blade half onto the first, forming the full blade. The glue along the blade and webbing connections dried for several hours, then a demolding team removed the blade from the mold and sent it to Building 2 blade cut and trim. Repair and gluing employees wore respiratory protection that included either half-mask air purifying respirators with organic vapor cartridges and snap-on N95 particulate prefilters or hooded powered air purifying respirators with combination organic vapor and P100 cartridges. Those not wearing a respirator with built-in eye protection wore safety glasses. Some wore MicroMAX coveralls; all wore nitrile gloves of varying thickness and cuff length depending on the task.

\section{Blade Cut and Trim}

While the blade molding process creates a strong, flexible blade, additional finish work is necessary to create the final aesthetic, structural, and aerodynamic characteristics desired by the customer. During mold closing, glue squeezes out of the seams between each half of the blade and the connections with the webbing. Most of the exterior ridges of dried glue and cured excess fiberglass were removed by a robot equipped with cutting/sanding tools and local exhaust ventilation. Employees, split into teams working on either the inside or the outside of the blade, then manually finished cut and trim work. First they finished cutting and trimming the exterior seams using angle grinders with local exhaust ventilation attachments connected to the building's central exhaust system. All cut and trim work on the blade interior was done manually, not by the robot. The robotic and manual cutting and trimming serve the dual purposes of removing excess material from the blade and preparing the surface to receive the finishing fiberglass resin patches applied next.

Employees laid up fiberglass resin patches (shown below in Figure 1, made of polyester fiberglass, a peroxide activator, and a polyester resin comprised of approximately $40 \%$ styrene) around interior and exterior blade seams, and did exterior surface prep work so the blade became ready for an exterior coating in the finishing and assembly department. Outside blade cut and trim employees wore either half-mask or full facepiece, air purifying respirators, or hooded powered air purifying respirators, with organic vapor cartridges and snap-on N95 prefilters. For dermal protection they wore MicroMAX coveralls and either leather (for cut and trim work) or nitrile (for laying up fiberglass patches) gloves. Employees making safety platforms wore the same dermal PPE, and a powered air purifying respirator with organic vapor cartridges. 


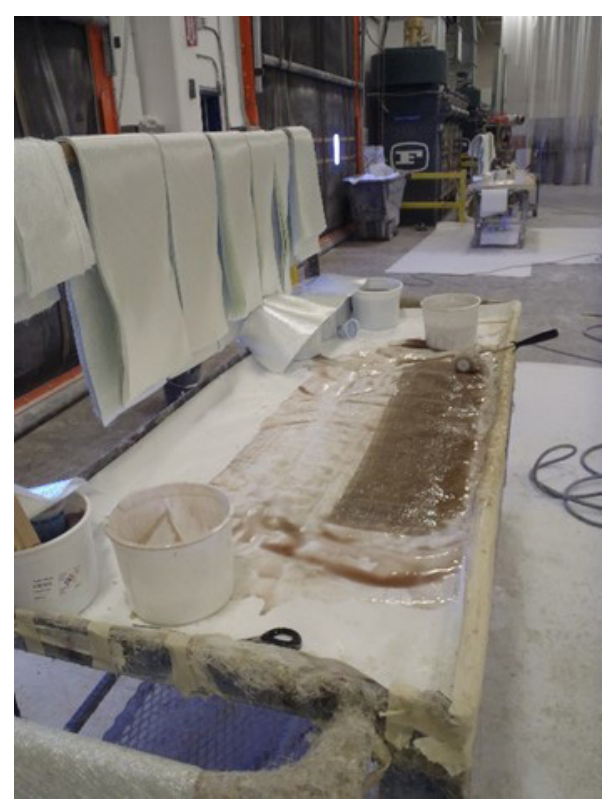

Figure 1. A resin-impregnated fiberglass patch, ready to be applied to either the interior or exterior blade seam. Photo by NIOSH.

The company managed inside blade cut and trim work as a permit-required confined space entry, continuously supervised by an entry attendant who took air quality measurements inside the blade approximately every 15 minutes. Inside cut and trim employees wore full facepiece supplied air respirators (continuous air supply mode), hooded chemical protective coveralls, nitrile gloves, a headlamp, and boot covers. They first completed any grinding needed inside the blade, then laid up fiberglass/resin patches after vacuuming out any grinding dust. Whenever employees began laying up the fiberglass patches, they also brought two centrifugal fans to the base of the blade to blow air from the surrounding area into the blade, attempting to dilute and flush out the vapors that built up inside.

\section{Finishing and Assembly}

Finishing and assembly employees complete several tasks on each blade. Many were cosmetic, but here lightning rods, external aircraft warning lights, safety platform installation, and final balancing occurred. Teams power sanded (sanders were connected to local exhaust ventilation attachments) exterior blade surfaces for about 20 minutes each to prepare the blade to receive a final coat of styrene-containing paint. Sanders and painters were required to wear respiratory protection during this work. In addition to safety glasses, they wore N95 filtering facepiece respirators when sanding and half-mask elastomeric respirators with organic vapor cartridges and snap-on N95 prefilters cartridge covers when painting. Some employees elected to wear higher levels of respiratory protection at times, for example, some wore full facepiece air purifying respirators with P100 cartridges when a blade needed more sanding than usual. The finishing and assembly department was a hearing conservation area; employees wore disposable earplugs (noise reduction rating of 33). Dermal PPE used by employees varied depending on individual preference, and included cotton or nitrile gloves, and MicroMAX sleeves, or coveralls. Figure 2 below shows a blade ready to be finished. 


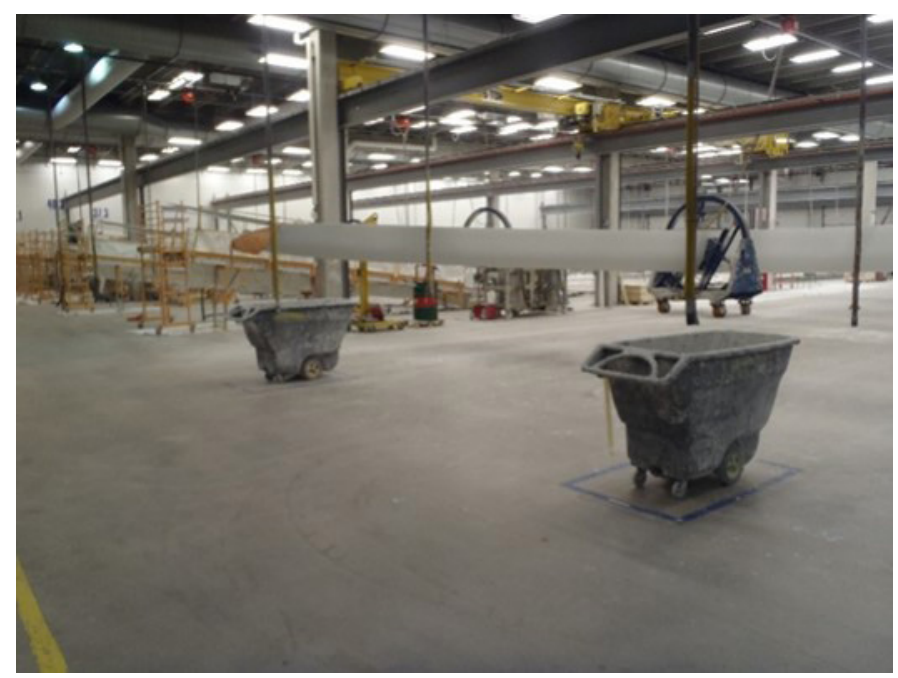

Figure 2. A blade ready for finish coating and final assembly. Photo by NIOSH.

Also here the safety platform "donuts" were placed into the root of the blade, as shown below in Figure 3. This component is a fiberglass laminate donut-shaped flat structure. It serves as a platform on which field services staff can stand when they enter a blade that is already installed onto a wind turbine at a power generation site. Historically, the company connected the donut to the blade root using styrene-containing resin fiberglass laminate patches. During our evaluation they reduced styrene exposure associated with this task by substituting a styrene-free two-part caulk adhesive thought by the company to contain only trace levels of xylene.

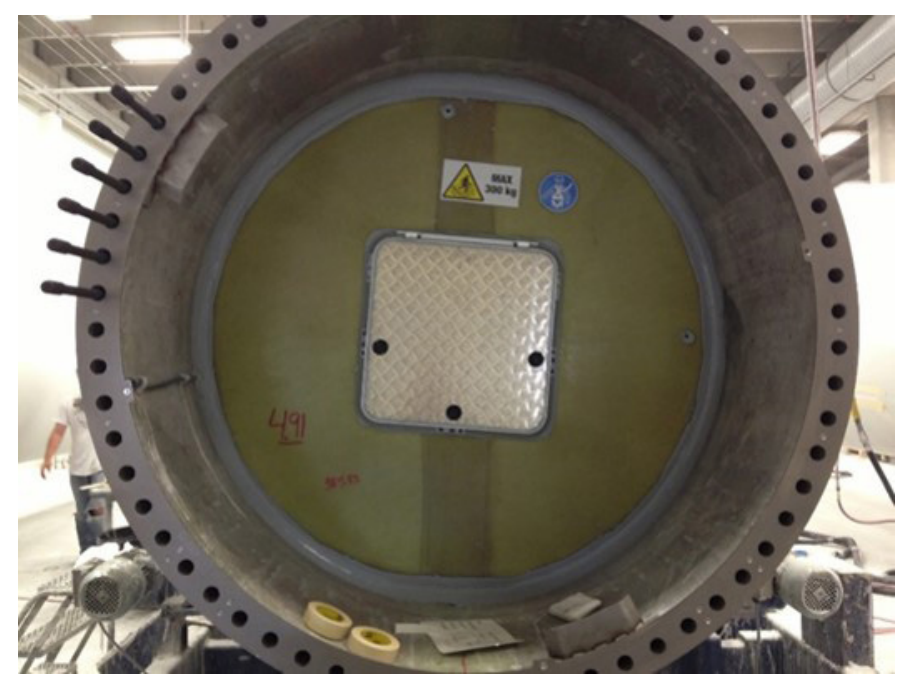

Figure 3. View of blade from the root, looking at the safety platform that has been affixed to the blade with gray colored adhesive. Photo by NIOSH. 


\section{Web Molding}

The web molding department constructs the blades' interior bracing, called "webs" or "webbing," which run almost the entire length of the blade they are placed within. The process uses a vacuum assisted resin infusion process like blade molding, though the relative amount of wood compared to fiberglass is much greater in web molding than in blade molding. A second important difference as it relates to potential employee exposures is that web molding uses no gel coat. Several web molds during resin infusion are shown below in Figure 4.

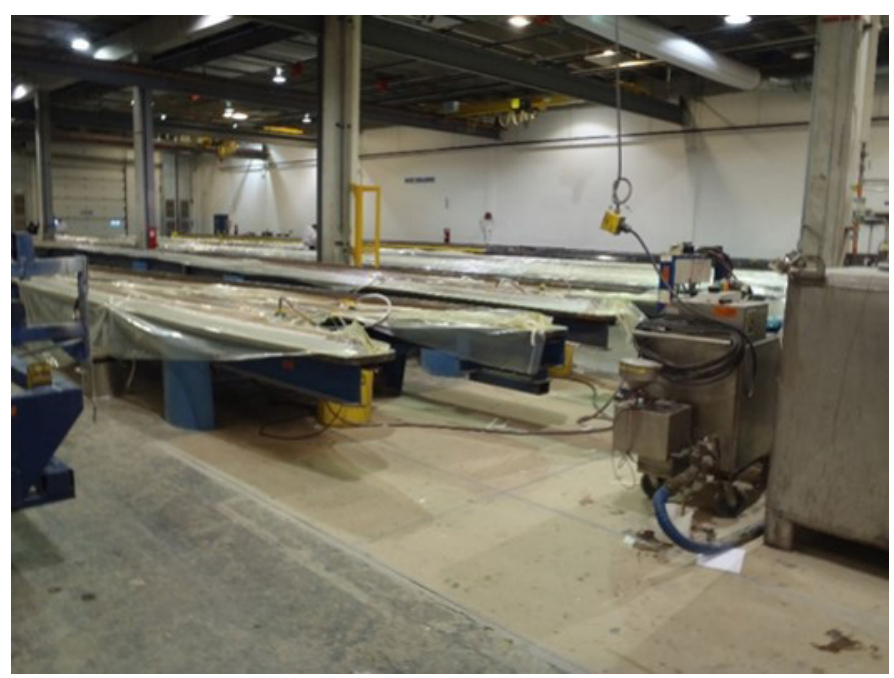

Figure 4. Several web molds during resin infusion. Photo by $\mathrm{NIOSH}$.

\section{Web Cut and Trim}

Generally, the grinding tasks here were similar to blade cut and trim, but the need for grinding was not as extensive. No permit-required confined spaces were associated with web cut and trim. Employees wore safety glasses and steel toe boots. When they were grinding or cutting the webs, they also wore MicroMAX coveralls, nitrile and leather gloves, and a respirator with P100 filters. Respirator users in this department had their choice of half-mask, full facepiece, or hooded powered air purifying respirators. Once the webs were assembled and finished, they were stored temporarily in this department, as shown below in Figure 5, until called for in blade molding. 


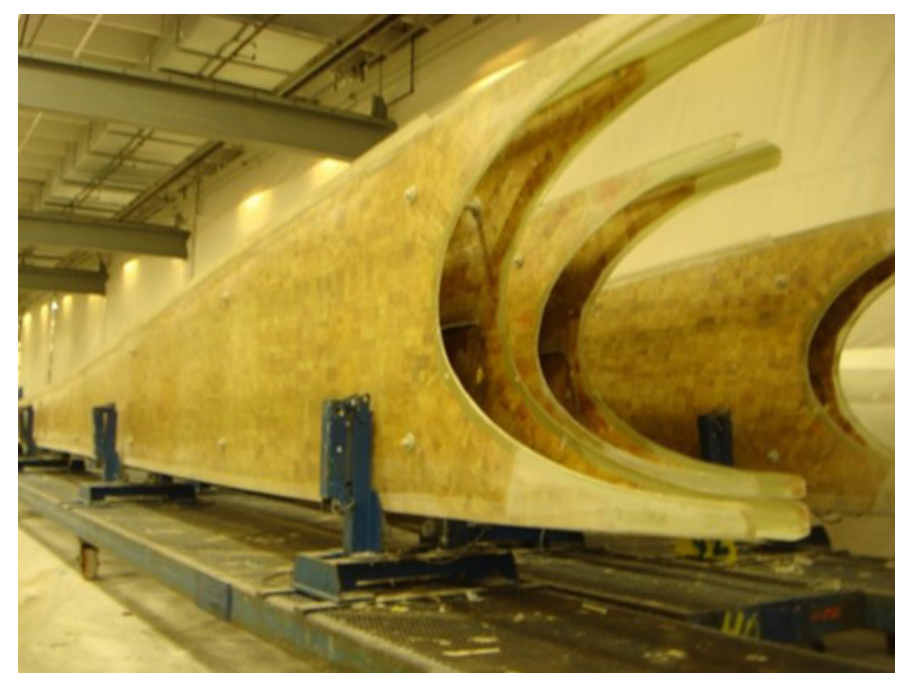

Figure 5. Three webs on storage racks awaiting transfer to Building 1. Photo by NIOSH.

\section{Bushing Winding}

Bushings serve as the connection pins between a blade and a turbine. Several dozen bushings around the open root of the blade are inserted and bolted onto a turbine at a power generation site in the field. The employees create individual bushings by hand gluing together 3-foot tapered pieces of balsa wood (about 4-inch diameter) and about 1-foot metal rods (about 4-inch diameter). Using a winding machine, they wind each bushing with fiberglass sheet/ string that is about 1.6 inches wide. At the time of the June 2013 visit, the bushing winding station was located in a blade mold room, so bushing winders were potentially exposed to styrene. They wore half-mask elastomeric respirators with organic vapor cartridges when gel coating occurred. By our June 2013 site visit, bushing winding had moved to Building 2 close to finishing and assembly. No gel coat spraying is done in Building 2. Bushing winders wore safety glasses and cotton gloves under nitrile exam gloves, and had access to disposable sleeve covers.

\section{Kitting}

The kitting department supports other departments by creating precut "kits" of blade- or web-specific fiberglass and balsa wood sheets. For example, the kitting department cuts the fiberglass patches used in blade cut and trim. They also sew together the balsa wood mats used in blade and web molding. Kitting employees also create the capillary tube laced plastic top sheets through which resin is infused during blade and web molding. All employees wore safety glasses; employees creating the kits also wore MicroMAX pants and long-sleeve shirts.

\section{Methods}

In March 2013, we walked through the facility to observe work practices, understand the flow of materials and personnel through the facility, collect area air samples to screen for volatile organic compounds, review records, and make arrangements for subsequent 
evaluations. In June 2013, we evaluated employee exposures to airborne styrene, xylene, and dust while obtaining informed consent from employees to participate in the medical evaluation. In July 2013, a NIOSH medical team evaluated employees for signs of styrene exposure, for lung function, and for color and contrast vision function. The objectives for this health hazard evaluation were:

- Evaluate employee exposures to airborne styrene, dust, and xylene and identify opportunities for further exposure reduction.

- Estimate styrene exposure from potential inhalation and dermal routes by measuring styrene metabolites in urine at the end of a work shift.

- Assess employees' color and contrast vision, given the potential neurotoxicity of styrene.

- Evaluate employees' lung function in relation to styrene and dust exposure.

\section{Air Sampling and Ventilation Assessment}

\section{Air Sampling}

During the March 2013 visit, we collected two short-term area air samples to screen for volatile organic compounds and to determine if styrene was the predominant airborne solvent. One sample was collected in blade molding during resin infusion, the other was collected in blade cut and trim near a table where employees prepared fiberglass laminate patches with activated resin. We also used a direct reading HNU photoionization detector, model DL-101, to estimate volatile organic compound concentrations in blade molding and blade cut and trim. This meter was factory calibrated to isobutylene; we estimated styrene concentrations by multiplying meter values by 2.7 per the manufacturer's recommendation. In June 2013, we collected full-shift personal air samples for styrene, particulates, and xylene. Historically, the adhesive used in Building 2 to attach safety platforms to the roots of finished blades contained styrene, but in October 2012 the company changed to a styrenefree adhesive suspected of containing small amounts of xylene. The air sampling methods involving laboratory analysis are below in Table 1.

Table 1. Air sample analytes, number, and method of collection and analysis [NIOSH 2016]

\begin{tabular}{lcc}
\hline Substance & Number of samples & NIOSH method \\
\hline Particulates & 29 & 0500 \\
Styrene & 74 & 1501 \\
Xylene & 2 & 1501 \\
Volatile organic & 2 & 2549 \\
compounds & & \\
\hline
\end{tabular}


We used a TSI DustTrak, model DRX 8533, direct reading aerosol meter with in-line tared particulate filter (subsequently analyzed per NIOSH Method 0500) to characterize particulate mass concentration and size in blade cut and trim. This light-scattering laser photometer simultaneously estimated respirable particulate mass concentration and total particulate mass concentration. The aerosol meter was factory calibrated with Arizona road dust, which may have different light-scattering and aerodynamic properties than the dust in blade cut and trim. To account for this difference, we compared the total mass concentration on the in-line filter with the total mass concentration estimated electronically by the aerosol meter. We found that the in-line filter mass concentration was 9\% lower than that estimated by the aerosol meter. Therefore, the results for the aerosol meter overestimate the true concentration.

\section{Ventilation Assessment}

We evaluated general building exhaust in blade molding, finishing and assembly, and blade cut and trim. We also measured representative local exhaust ventilation ports on grinders and sanders in finishing and assembly and cut and trim areas. To evaluate the general building exhaust system, we took measurements at each exhaust plenum along the walls of both buildings and the floors of Building 1 (Building 2 did not have floor exhaust vents) using a multipurpose TSI model EBT731 Balometer ${ }^{\circledR}$. We placed the $2 \times 2$ foot air capture hood over the exhaust grilles in the floor to directly measure the volumetric flow rate of exhaust air at those locations. For the wall exhaust, we used the detachable $1 \times 1$ foot velocity sensor with 16-point measurement grid to measure and average air velocities.

Several wall exhaust locations in the cut and trim areas of Building 2 had slot intakes of varying dimensions. We measured air velocities entering each slot with a TSI model 9555 hot wire anemometer. Rough filters were in place over each exhaust grill when we collected these measurements. We collected these velocity measurements at equal distances across each slot, averaged them, divided the result by the total open area, then summed these values to calculate total volumetric airflow for each exhaust grille. We used the same hot wire anemometer to measure air velocity from tool (grinders and sanders) hose suction lines by removing the suction hose from the tool and placing the hot wire probe over the open area of the tool.

\section{Medical Testing}

During the first site visit, we conducted informal private interviews with employees to understand their exposure and health concerns.

We recruited employees about 2 weeks prior to the start of medical testing. They were given the opportunity to provide written informed consent. During the week of July 8-13, 2013, every employee was invited to participate in testing. After they provided written informed consent, we asked each participant to take an interviewer-administered, computerbased questionnaire and tests for visual acuity, visual contrast, and color vision. They took breathing tests known as spirometry and exhaled nitric oxide tests. We also asked participants to give a urine sample to be tested for styrene metabolites. Following the survey, we mailed personal results to each participant at his or her home address, with recommendations for 
follow-up of abnormalities.

The questionnaire (Appendix B) included questions from the American Thoracic Society adult respiratory questionnaire [Ferris 1978], the Third National Health and Nutrition Examination Survey (NHANES III) [Department of Health and Human Services 1996], and the European Community Respiratory Health Survey [Grassi et al. 2003]. Questions addressed respiratory and dermatological symptoms, asthma and other medical diagnoses, smoking history, work history and practices, PPE use, and demographic information. We also asked participants about medical conditions that could affect vision, such as glaucoma, macular degeneration, eye surgery, and amblyopia.

All participants were tested for visual acuity using a Rosenbaum pocket vision screener. Participants then had their color vision tested binocularly with the Lanthony desaturated D-15, a color arrangement test recommended for detecting acquired vision loss [Fox and Boyes 2013]. The color vision test detects complete absence of a particular cone (dichromacy) and presence of a defective cone (anomalous trichromacy). Participants wore daylight filtering glasses and arranged 15 caps in color order. Visual contrast was tested with a Stereo Optical Company functional acuity contrast test (FACT). Participants were asked to say whether stripes pointed left, right, or vertically as these stripes became less contrasted. They repeated this five times at increasing frequencies. The test was performed one eye at a time, and participants were randomized as to which eye they started with to decrease the population-level effect of learning.

We assessed airway inflammation and uncontrolled asthma with an Aerocrine NIOX Mino®, a hand-held device that measures nitric oxide in exhaled air. Elevated fraction of exhaled nitric oxide (FeNO) levels can indicate airway inflammation, particularly eosinophilic inflammation. The test has shown success in detecting nonasthmatic eosinophilic bronchitis as well, which can be work-related [Pala et al. 2011]. FeNO can be affected by smoking, consumption of nitrate-rich foods, steroids, respiratory illness, and exercise. The test was administered in the following manner. Participants held the device in their hands, seated across from a mirror. We asked them to place the mouthpiece in their mouth, inhale to total lung capacity, and then breathe out evenly for 10 seconds. The machine gave feedback about the strength of the exhalation, which participants could see in the mirror, allowing adjustment of the strength of the exhalation as needed. Participants were allowed six trials; we considered a single good score sufficient. We asked participants about activities that could affect their score, such as consumption of nitrate-rich foods, smoking, exercise, upper respiratory illnesses, and use of certain medications.

A NIOSH technician administered spirometry tests using a dry rolling-seal spirometer interfaced to a personal computer following American Thoracic Society guidelines [Miller et al. 2005]. Unless contraindicated, participants with any spirometric abnormality were given a bronchodilator to determine reversibility, using four puffs of a beta-agonist (albuterol). In some cases, such as if a participant reported asthma, a bronchodilator was offered despite normal spirometry.

Employees were given an empty urine cup identified by their participant identification number and asked to return a sample at the end of their shift. This time was chosen because 
studies have shown that peak excretion occurs within 1 hour of the end of shift [ACGIH 2016b] except in the face of excessive alcohol consumption, which delays excretion [Wilson et al. 1983]. In heavy drinkers, end-of-shift sampling would thus be expected to underestimate exposure. Information about unusual work activities and alcohol consumption was collected when employees turned in urine. Urine samples were frozen immediately using dry ice, and overnight shipped to a Centers for Disease Control and Prevention lab. Samples were assayed for mandelic acid (MA), phenylglyoxilic acid (PGA), and two isomers of N-Acetyl-S-(phenyl-2-hydroxyethyl-L-cysteine) (PHEMA) using ultra high performance liquid chromatography coupled with an electrospray ionization triple quadrupole mass spectrometry method [Alwis et al. 2012]. The limits of detection were 12 nanograms per milliliter (ng/mL) for urinary MA, $12 \mathrm{ng} / \mathrm{mL}$ for PGA and $0.7 \mathrm{ng} / \mathrm{mL}$ for the PHEMA compounds, which were reported together. These metabolites represent the major products of styrene metabolism in humans (Figure 6).

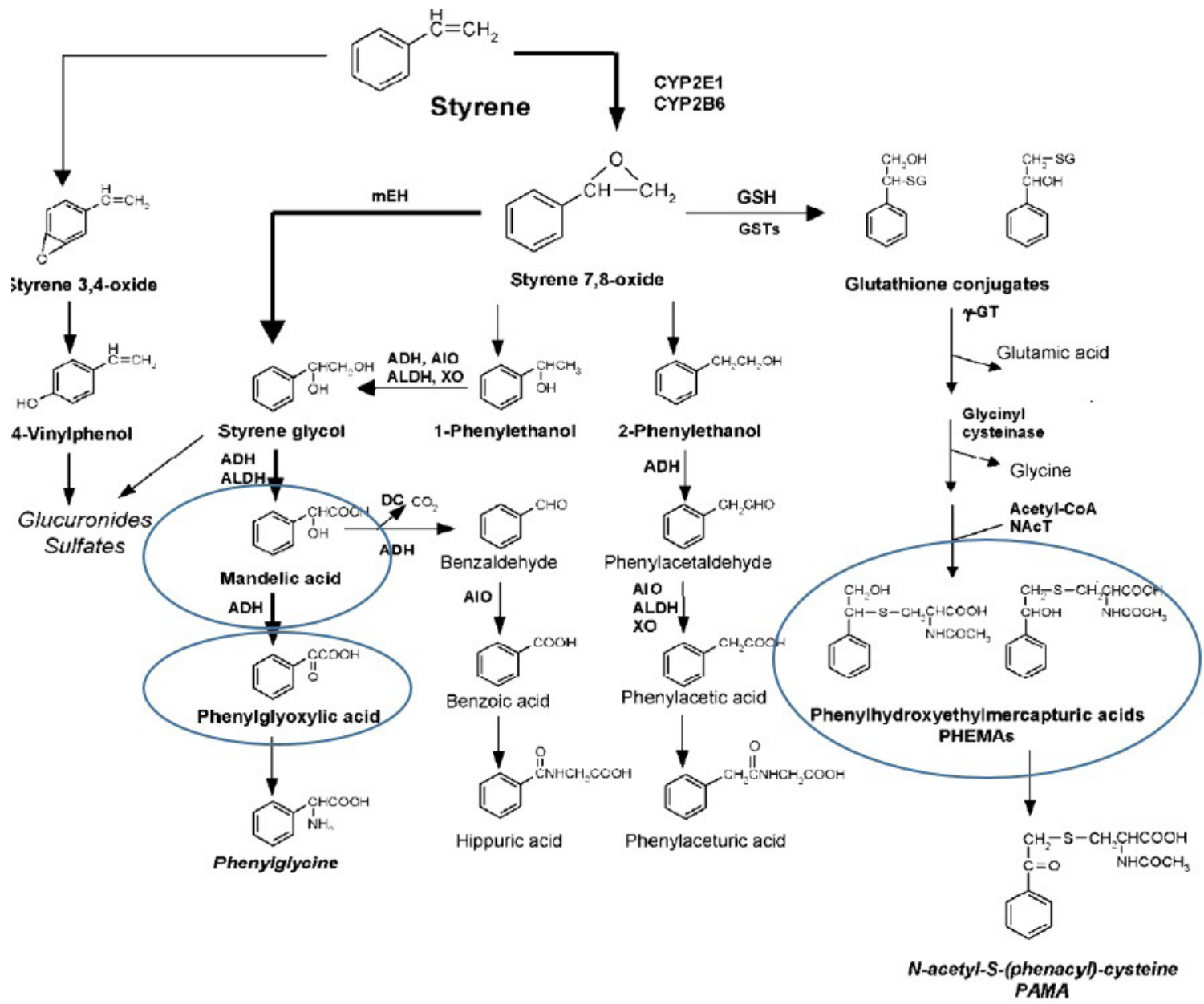

Figure 6. Styrene metabolism with major metabolites circled. Abbreviations: CYP2E1 and CYP2B6 = cytochrome $\mathrm{P}-450$ monooxygenase, $\mathrm{mE}=$ microsomal epoxide hydrolase, $\mathrm{ADH}$ : alcohol dehydrogenase, $\mathrm{AIO}=$ aldehyde oxidase, $\mathrm{ALDH}=$ aldehyde dehydrogenase, $\mathrm{XO}=$ xanthine oxidase , $\mathrm{DC}=$ decarboxylase, $\mathrm{GSH}$ = glutathione, $\mathrm{GSTs}$ = glutathione $\mathrm{S}$-transferases, $\mathrm{y}$-GT = gammaglutamyl transpeptidase, NAcT = N-acetyltransferase. Figure from Manini et al. 2002. 


\section{Statistical Analysis}

Statistical analyses were conducted using SAS software version 9.3 and JMP software version 10.0.1. We report results as standardized morbidity ratios (SMRs) or odd ratios. An SMR above one indicates that the prevalence of the health problem is more common among participants than expected. An SMR of one indicates that the health problem is as common among participants as expected. An SMR below one indicates that the prevalence of the health problem is less common among participants than expected. Similarly, an odds ratio above one indicates that the odds of that health problem or outcome in the group of interest is greater than the odds in the reference group, while an odds ratio of one indicates the odds are equal, and an odds ratio of less than one indicates that the odds of the outcome are less in the group of interest than in the reference population.

To determine statistical significance we used $P$ values and $95 \%$ confidence intervals for the SMRs and odds ratios. $P$ values of 0.05 or less were considered significant, and those between 0.05 and 0.1 were considered borderline. The confidence interval gives the statistical range for an estimate. Wider ranges suggest we are less sure about the estimate than narrower ranges. A range that includes one indicates the result was not statistically significant. For those that appeared to be borderline, we calculated $90 \%$ confidence intervals; those that were significant at that level are indicated in the results as borderline, though $90 \%$ confidence intervals are not reported.

\section{Exposure Variables}

\section{Job Location}

To evaluate any health effects associated with general work location, we separated employees into groups on the basis of job location as determined by self-reported job department and title. Employees in blade molding, mold prep, kitting, and bushings were placed into the "Building 1" group $(\mathrm{n}=189)$. Employees in post-molding jobs or webbing were assigned to the "Building 2" group $(\mathrm{n}=67)$. Office employees and employees in the yard and warehouse were grouped together $(n=56)$; the office area had separate ventilation from the production areas, and outdoor employees do not work in the indoor production areas. Finally, employees such as maintenance, quality control, and janitorial staff were placed in an "all-over" category $(n=42)$, because their jobs take them to all areas of the plant.

\section{Current Styrene Exposure}

Urinary styrene metabolites were reported by the lab in $\mathrm{ng} / \mathrm{mL}$. Spot urine creatinine was also reported for each employee, allowing us to normalize results to individual kidney function. To get an estimate of exposure that could be easily compared to published data, we calculated "current styrene exposure" for each individual using the method described by the American Conference of Governmental Industrial Hygienists (ACGIH) for the biological exposure index as shown in Formula 1 [ACGIH 2016a]:

Current styrene exposure $=(\mathrm{MA}+\mathrm{PGA})$ milligrams/gram creatinine

(Formula 1) 
Current styrene exposure is traditionally reported in milligrams ( $\mathrm{mg}$ ) of metabolites per gram (g) of creatinine, and we adjusted the units accordingly. We used this measure to compare departments to one another and to look at the mean and median exposure in the plant. To reduce the effect of outlier values, we log-transformed (using the natural log) current styrene exposure to compare it to our health outcomes using linear and logistic regression models. We divided exposure into quartiles so that $25 \%$ of employees were in each quartile. We used the quartile cut-offs generated to place different job titles into the 4 quartiles by mean exposure. In certain cases, we divided the workforce into those with exposure above or equal to the median and those with exposure below the median and compared the odds of symptoms or health outcomes of the more highly exposed half of the workforce against the less exposed half of the workforce. We also sometimes used the log of each metabolite (corrected for creatinine) separately to check for health effects.

\section{Cumulative Styrene Exposure}

To estimate employees' exposure over the course of their entire work history at this plant, an average current styrene exposure was assigned to each department/job title combination on the basis of those employees who participated in the study. For those job titles for which no employees turned in a urine sample, we assigned a current styrene exposure value from another job in the same department (e.g., a "team lead" current styrene exposure for a "supervisor" in the same department) or a nearby department (e.g., the "webs" current styrene exposure for all "web cut and trim" employees). These current styrene exposures were then multiplied by the number of months an employee had spent in that job. This was calculated for every job in a given employee's history, and summed to give a relative indicator of cumulative styrene exposure. We followed a similar method for each of the three metabolites. As with the current exposure variable, we modelled using the natural logtransformed cumulative styrene exposure, then compared it to health outcomes in linear and logistic models.

Because changes related to styrene exposure occurred at the plant in the years preceding our evaluation, we also created several variables to take this into account. A reduced styrene gel coat was substituted in place of a higher-styrene gel coat in October 2012. Thus, using self-reported hire date from the questionnaire, we created a variable to indicate whether an employee was hired before or after this change. We also created a variable for each employee's tenure before and after October 2012 and a variable that reported the estimated current styrene exposure for the highest exposure job each employee ever held.

\section{Dust Exposure}

Employees were classified by dust exposure based on industrial hygiene data (summarized in the interim letter of September 2013), task-questions on the questionnaire, NIOSH investigator observations, and discussions with employees. We used a three category matrix, where employees were labelled as (1) working in a job that generated dust, (2) working near a dusty job, and (3) not working near dust. 


\section{Health Outcomes}

\section{Symptoms}

We examined questionnaire responses in several ways. We created one outcome variable, which we called "asthma-like symptoms." Asthma-like symptoms were defined as any of the following: current use of asthma medicine, wheezing or whistling in the chest in the past 12 months, awakening with a feeling of chest tightness in the past 12 months, or attack of asthma in the past 12 months. This definition may capture people who have asthmalike symptoms, but have not been diagnosed [Grassi et al. 2003]. For certain symptoms, we also assessed the percent of employees whose symptoms improved away from work or first began after beginning work at the plant, possibly indicating work relatedness. For such symptoms, we examined the percent of employees who reported each symptom. In addition, we compared certain symptoms to NHANES III using SMRs. We then compared symptoms to exposures using logistic regression to calculate odds ratios and corresponding $95 \%$ confidence intervals. We controlled for smoking (current, former, never), sex, race, and age $(\geq 40$ years, $<40$ years).

\section{Color Vision}

For color vision, using the guidelines published by Torok [2014] and Geller [2001], we assigned each employee a color confusion index (CCI) and a color angle. The CCI represents the ratio between a given person's score and a perfect score; a perfect test has a CCI of 1.0. If the CCI was greater than 1.65, we considered the employee to have abnormal color vision. The color angle then determined the specific kind of color vision deficit: protan ( -2 to 29 ), deutan ( -30 to -2$)$, tritan ( -90 to -65$)$, or unknown (anything else) (Figure 7 ). We created grouped color vision outcomes; protan and deutan (both red-green color blindness) were grouped together; we analyzed tritan and unknown both separately and together. Both protan and deutan tend to be congenital and not acquired. Tritan is extraordinarily rare congenitally $(<0.1 \%$ of the population) and is generally considered to be an acquired color deficiency [Kalloniatis and Luu 2007]. We postulated that unknowns might represent combinations of two color deficits, such as tritan plus deutan, or even complete color vision loss, as acquired color vision loss has been shown to progress from tritan to tritan plus deutan to complete color blindness [Fox and Boyes 2013; Geller and Hudnell 1997].

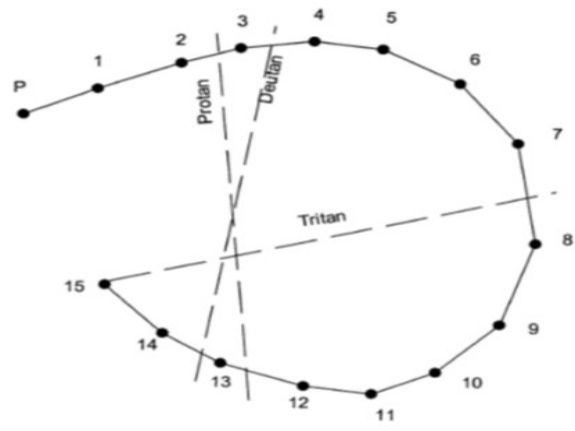

Figure 7. Scoring template for Lanthony desaturated D-15 [Geller 2001]. 
For the entire plant, we used the SAS STDRate procedure to calculate the SMRs and exact Poisson confidence limits to compare the prevalence of color vision abnormalities with those expected to occur congenitally in a western population [Kalloniatis and Luu 2007]. We note that the available reference values only included protan, deutan, and tritan specifically. We assumed that the unknown category did not represent a congenital abnormality. We grouped protan, deutan, tritan, and unknown for comparisons to the overall approximate estimate of congenital overall color deficiencies. To elucidate the relationship with exposures, we used the CCI, color angle, color blindness type, and grouped color blindness as our outcomes. We used linear regression models and multinomial logistic regression models to compare these color vision outcomes to exposures, controlling for visual acuity, diabetes, glaucoma, cataracts, macular degeneration, age, alcohol in the last 24 hours, and smoking status.

\section{Contrast Vision}

We interpreted contrast vision testing results using the method described in the FACT instruction manual [Ginsburg 1993]. Figure 8 shows a photo of the test. Frequencies increase from 1.5 to 18 cycles per degree from A-E. Each frequency has nine different circles of progressively decreasing contrast (the lines get lighter). Employees had to identify which direction (left, vertical, right) the lines pointed. The highest correctly identified spot was marked, giving each employee a score of 1-9 at each frequency. These scores were then converted to contrast sensitivity scores as described in the manual [Ginsburg 1993]. These scores for each eye were plotted on a graph vs. spatial frequency as seen in Figure 9. The gray area marks the range of "normal" values. Any score falling below the gray area was classified as abnormal for that spatial frequency for that eye. Additionally, anyone whose scores differed by more than two contrast values at one frequency, or one contrast value at two adjacent frequencies, was also classified as abnormal. We used the scores to create a worst, best, and average score at each frequency for each person; we report analyses using the average score because the results differed little from those for lowest and best scores at each frequency. These continuous variables were compared to exposure variables using linear regression models controlling for visual acuity, diabetes, glaucoma, macular degeneration, cataracts, age, alcohol in the last 24 hours (as a surrogate for overall alcohol consumption), and smoking. The majority of these confounders did not have a significant effect in our model; rerunning the model without them did not significantly change the results, so for consistency with prior literature, we reported the fully adjusted results. 


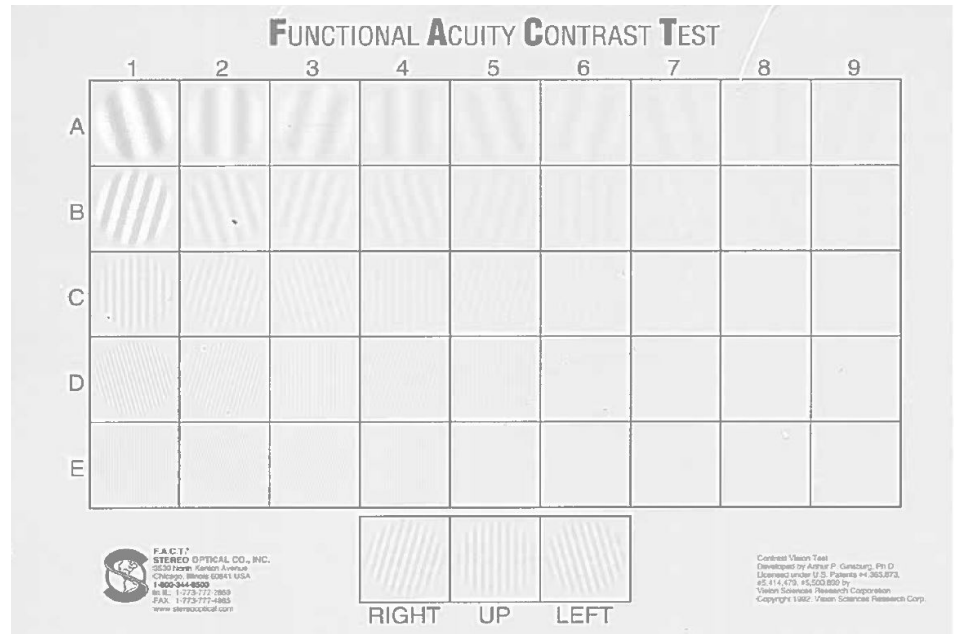

Figure 8. Functional acuity contrast testing card. Five frequencies, $A-E$, extend down the edge of the card. The frequency increases from $A$ to $E$, meaning the dark lines get thinner and closer together. At each frequency, there are nine different tests, and contrast decreases as the score increases (1-9). Photo by NIOSH.

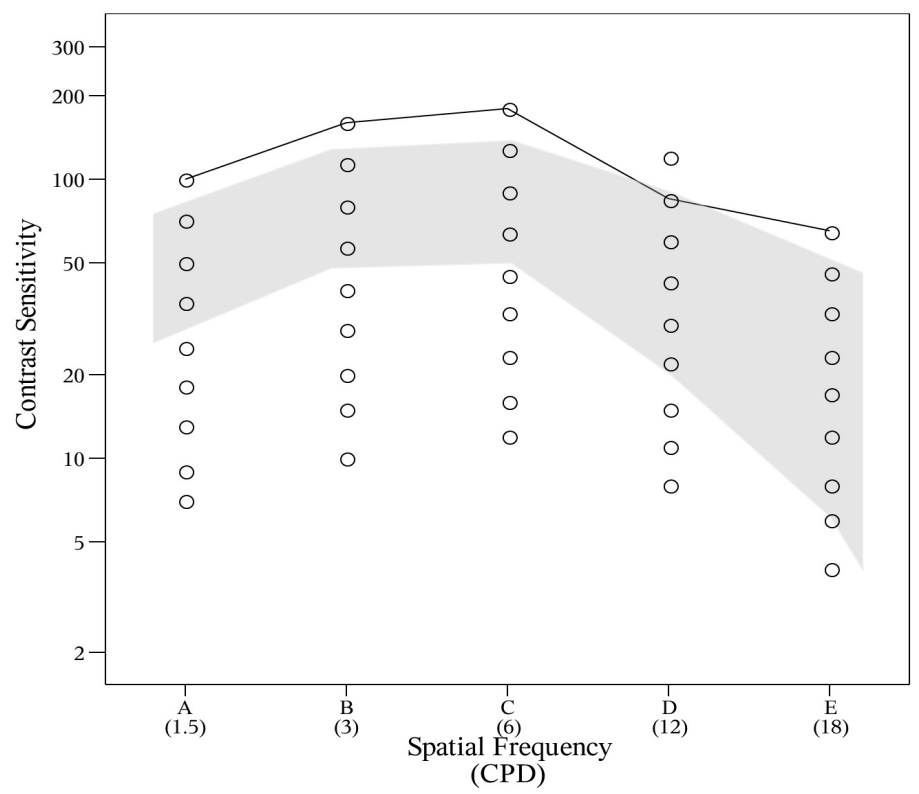

Figure 9. Graph of contrast sensitivity for one eye. The shaded area represents "normal" scores. The line represents one person's actual score. CPD = cycles per degree. Image by NIOSH. 


\section{Fraction of Exhaled Nitric Oxide}

FeNO results above 50 parts per billion ( $\mathrm{ppb}$ ) were considered abnormal, according to the American Thoracic Society guidelines [Dweik et al. 2011]. FeNO scores below the limit of detection were treated using the formula limit of detection $/(\sqrt{2})$. Though 50 is considered the cut-off for diagnosis of asthma, studies indicate that values in nonsmoking healthy adults are likely much lower [Dweik et al. 2011]. To make sure we accounted for this variation within the range of normal, we used this as a continuous outcome variable in linear models to compare to exposures. We corrected for smoking status, respiratory illness in the last 7 days, and ingestion of nitrate-rich foods. The group of employees who reported steroid use (four people) was excluded.

\section{Spirometry}

We compared spirometry results to reference values based on a participant's age, sex, height, and race, which were generated from NHANES III data [Hankinson et al. 1999]. Each participant's largest forced vital capacity (FVC) and forced expiratory volume in the first second $\left(\mathrm{FEV}_{1}\right)$ were selected for analysis. We classified participants as having airway obstruction if they had a ratio of $\mathrm{FEV}_{1} / \mathrm{FVC}$ below the respective lower limit of normal (5th percentile) with a normal FVC. We defined restriction as a normal $\mathrm{FEV} / \mathrm{FVC}$ ratio with FVC below the lower limit of normal. We classified participants with $\mathrm{FEV}_{1} / \mathrm{FVC}$ ratio and $\mathrm{FVC}$ below the lower limit of normal as having mixed obstructive and restrictive abnormalities. We defined reversibility as an increase in $\mathrm{FEV}_{1}$ of at least $12 \%$ and $200 \mathrm{~mL}$ after bronchodilator administration [Pellegrino et al. 2005].

We used the outcome variables (normal, obstruction, restriction, and mixed spirometry) and compared to NHANES III population levels using SMRs. We also calculated summary statistics for the continuous outcomes percent predicted $\mathrm{FEV}_{1}$, percent predicted FVC, and $\mathrm{FEV}_{1} / \mathrm{FVC}$. We used these same outcome variables in linear regression models to compare spirometry outcomes to exposures, controlling for smoking, body mass index (BMI), and age in certain cases.

\section{Other}

To assess employee PPE use during the time of medical testing, we asked all employees about the PPE they used during certain tasks (questions 20 and 20.1). We then used this information to create yes/no variables for each type of respirator and skin protection. We also created a summary yes/no variable for any kind of respiratory protection and one for any kind of skin protection. We looked at the percentage of employees reporting each kind of PPE use within different exposure groups. We also asked about previous employment in certain industries, including auto body, reinforced plastics, and fiberglass. We used these variables in certain models to control for exposures prior to the start of employees' tenure at this plant. They did not affect the results, and were subsequently removed from the models, which are reported without this adjustment. 


\section{Results}

We evaluated employee airborne exposures, local exhaust ventilation, and work practices several weeks before we assessed employee health and biological measures of exposure. Because the objectives of the exposure and health assessments were different, we present the results and discussion for each assessment separately.

\section{Air Sampling}

Qualitative area air sampling and safety data sheet reviews, confirmed that styrene was the volatile organic compound in greatest abundance at this facility. Summary results for styrene in personal air samples are in Table 2, and individual personal air sample results are shown in Appendix A, Tables A1 and A2. Table 2 shows the full-shift average exposures for employees who worked 8- or 10-hour shifts depending on production needs of the day. When employees worked longer than an 8-hour work shift, we adjusted the ACGIH threshold limit value (TLV®) according to procedures recommended by Brief and Scala [1975]. The NIOSH limit is not adjusted for extended work shifts and is appropriate for exposures up to a 10-hour workday during a 40-hour workweek. Only one department, blade cut and trim, had employee exposures that exceeded the NIOSH recommended exposure limit (REL) and unadjusted ACGIH limits; no styrene exposures exceeded the Occupational Safety and Health Administration (OSHA) permissible exposure limit (PEL). We also measured fullshift xylene exposures for two employees using a two-part caulk adhesive to affix the safety platforms to blade root interiors in finishing and assembly. Their exposures were 0.03 parts per million (ppm) and $0.04 \mathrm{ppm}$. These exposures were well below the full-shift NIOSH, OSHA, and ACGIH limits of 100 ppm. 
Table 2. Summary of full-shift personal air sample results for styrene, June 11-13, 2013

\begin{tabular}{|c|c|c|c|c|c|}
\hline Location, job & $\begin{array}{l}\text { Number of } \\
\text { samples }\end{array}$ & $\begin{array}{l}\text { Concentration, } \\
\text { range (ppm) }\end{array}$ & $\begin{array}{c}\text { Geometric } \\
\text { mean }\end{array}$ & $\begin{array}{l}\text { Geometric } \\
\text { standard } \\
\text { deviation }\end{array}$ & $\begin{array}{c}\text { \% samples } \\
\text { above lowest } \\
\text { OEL }\end{array}$ \\
\hline $\begin{array}{l}\text { Building } 1 \text {, gel coat } \\
\text { sprayer }\end{array}$ & 9 & $2.0-6.9$ & 3.90 & 1.55 & 0 \\
\hline $\begin{array}{l}\text { Building } 1 \text {, gel coat } \\
\text { machine operator }\end{array}$ & 7 & $2.6-5.0$ & 3.32 & 1.26 & 0 \\
\hline Building 1, other & 16 & $1.7-17$ & 5.40 & 1.85 & 0 \\
\hline $\begin{array}{l}\text { Building } 2 \text {, blade cut } \\
\text { and trim (total) }\end{array}$ & 24 & $2.1-66$ & 13.8 & 2.43 & $54^{*}$ \\
\hline inside & 9 & $6.9-66$ & 32.4 & 2.02 & $89^{*}$ \\
\hline outside & 9 & $2.1-40$ & 11.8 & 2.81 & $56^{*}$ \\
\hline attendant & 6 & $7.1-13$ & 8.55 & 1.26 & 0 \\
\hline $\begin{array}{l}\text { Building 2, finishing } \\
\text { and assembly }\end{array}$ & 12 & $1.3-9.9$ & 6.01 & 1.80 & 0 \\
\hline $\begin{array}{l}\text { Building 2, web } \\
\text { molding }\end{array}$ & 3 & $0.091-10.1$ & 1.39 & 11.1 & 0 \\
\hline $\begin{array}{l}\text { Building 2, safety } \\
\text { platform layup }\end{array}$ & 3 & $11-20$ & 14.2 & 1.36 & $33^{*}$ \\
\hline NIOSH REL & & 50 & - & - & - \\
\hline OSHA PEL & & 100 & - & - & - \\
\hline \multicolumn{2}{|c|}{ ACGIH TLV (10-hour adjusted TLV) } & $20(14)$ & - & - & - \\
\hline
\end{tabular}

*Percentages include samples that exceeded the 10-hour shift-adjusted TLV of $14 \mathrm{ppm}$.

Summary results for dust in personal air samples are in Table 3, and individual results are in Appendix A, Table A3. The results in Table 3 show the full-shift average exposures for employees who worked 8-hour or 10-hour shifts. All departments in Building 2 had employees with dust overexposures. Employees performing cut and trim tasks consistently had the highest dust exposures. Employees working inside blades doing cut and trim work had the highest dust exposures (up to 90 milligrams per cubic meter $\left(\mathrm{mg} / \mathrm{m}^{3}\right)$. All seven employees monitored while doing this work were overexposed to dust. The geometric mean dust concentration for this exposure group was more than three times the OSHA PEL for particulates not otherwise regulated. Occupational exposure limits and health effects for the substances evaluated are in Appendix C. 
Table 3. Summary of full-shift personal air sample results for dust, June 11-13, 2013

\begin{tabular}{lccccc}
\hline Location, job & $\begin{array}{c}\text { Number of } \\
\text { samples }\end{array}$ & $\begin{array}{c}\text { Concentration, } \\
\text { range }\left(\mathrm{mg} / \mathrm{m}^{3}\right)\end{array}$ & $\begin{array}{c}\text { Geometric } \\
\text { mean }\left(\mathrm{mg} / \mathrm{m}^{3}\right)\end{array}$ & $\begin{array}{c}\text { Geometric } \\
\text { standard } \\
\text { deviation }\end{array}$ & $\begin{array}{c}\% \text { samples } \\
\text { above } \\
\text { lowest limit }\end{array}$ \\
\hline $\begin{array}{l}\text { Building 1, bushing } \\
\text { winding }\end{array}$ & 2 & $0.16,0.28^{*}$ & - & - & 0 \\
$\begin{array}{l}\text { Building 2, blade cut } \\
\text { and trim (total) } \\
\quad \text { Inside }\end{array}$ & 11 & $4.9-90$ & 29.9 & 2.49 & 82 \\
$\quad \begin{array}{l}\text { Outside } \\
\text { Building 2, finishing }\end{array}$ & 7 & $16-90$ & 47.7 & 1.77 & 100 \\
$\begin{array}{l}\text { and assembly } \\
\begin{array}{l}\text { Building 2, web cut } \\
\text { and trim }\end{array}\end{array}$ & 9 & $4.9-39$ & 13.1 & 2.33 & 50 \\
\hline $\begin{array}{l}\text { OSHA PEL } \\
\text { (particulates not otherwise regulated) }\end{array}$ & $0.82-19 \dagger$ & 2.62 & 2.80 & 11 \\
$\begin{array}{l}\text { ACGIH guideline for "particles } \\
\text { (insoluble or poorly soluble) not } \\
\text { otherwise specified" }\end{array}$ & 10 & 11.7 & 2.94 & 43 \\
\hline
\end{tabular}

*One sample was for a partial shift (261 minutes) due to a sampling pump failure.

†The highest exposure occurred when the sander had a clogged local exhaust ventilation hose; no other exposure in this group exceeded $5 \mathrm{mg} / \mathrm{m}^{3}$ (AppendixA, Table A3).

We used the direct reading aerosol meter for approximately 1 hour to measure area aerosol concentrations in blade cut and trim, and in two areas where dust was not being generated by production processes: web molding and an office, for reference (Figure 10). While in blade cut and trim, the meter was moved periodically along the outside of the blade roots while employees used grinders. Concentrations of total dust increased from approximately $0.05 \mathrm{mg} / \mathrm{m}^{3}$ in the office, to approximately $0.27 \mathrm{mg} / \mathrm{m}^{3}$ in web molding, to nearly $25 \mathrm{mg} / \mathrm{m}^{3}$ during brief peaks (less than 10 seconds total) in blade cut and trim. Concentrations of respirable dust increased from nearly $0.01 \mathrm{mg} / \mathrm{m}^{3}$ in the office, to nearly $0.1 \mathrm{mg} / \mathrm{m}^{3}$ in web molding, to an average concentration of $0.73 \mathrm{mg} / \mathrm{m}^{3}$ (with brief peak concentrations above $3 \mathrm{mg} / \mathrm{m}^{3}$ ) in blade cut and trim. These results indicate that employees outside the blade are exposed to total and respirable particulate from inside blade cut and trim work. 


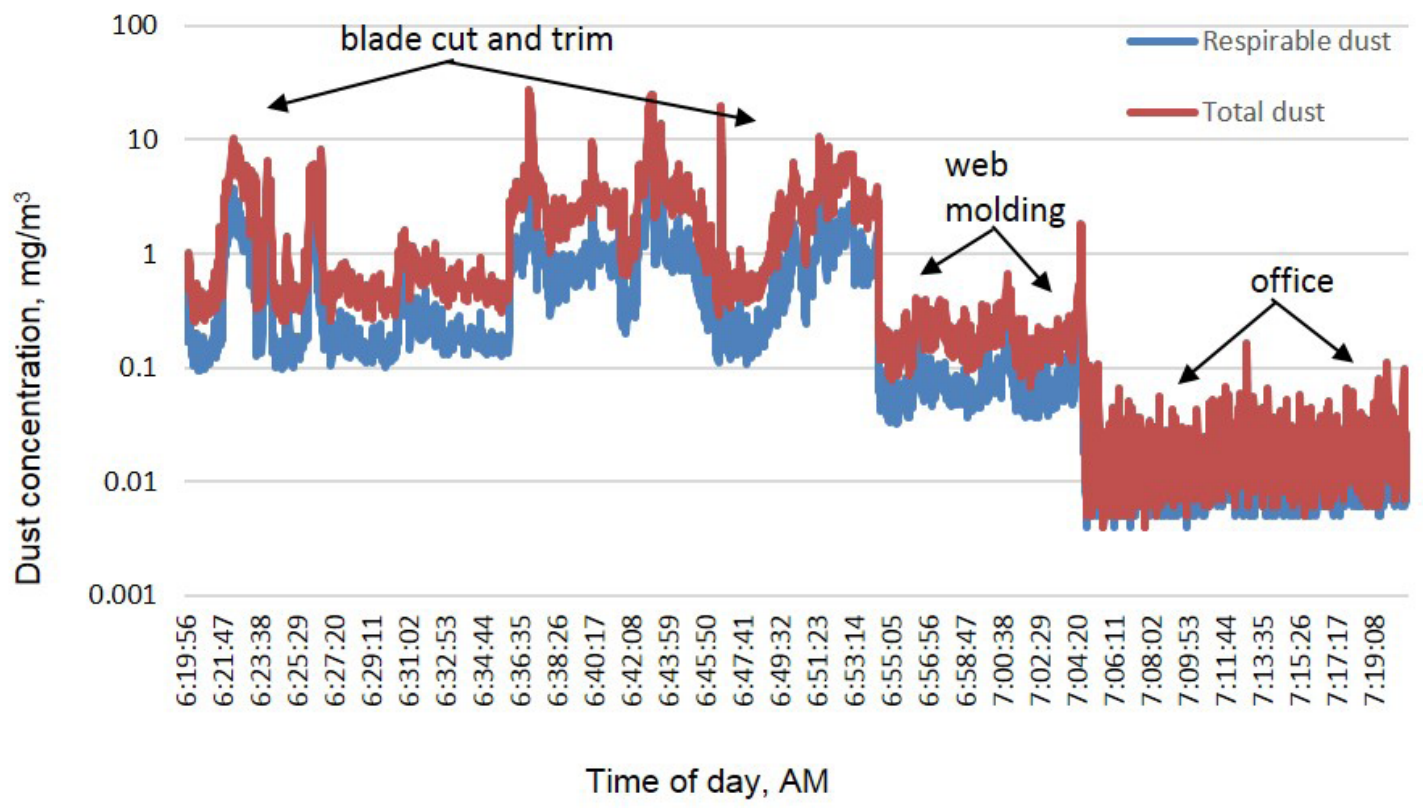

Figure 10. Area dust concentrations in Building 2.

Figure 11 shows forced air ventilation being supplied into the root of a blade while an employee does inside blade cut and trim work. The intakes for the supply air fans terminate just above the height of the blade. When employees used styrene-containing resin inside the blade, we measured styrene concentrations of 95 to $190 \mathrm{ppm}$ in the general area of the fan supply inlets. This indicated that the air supplied to the blade contained a high concentration of styrene during the time we measured.

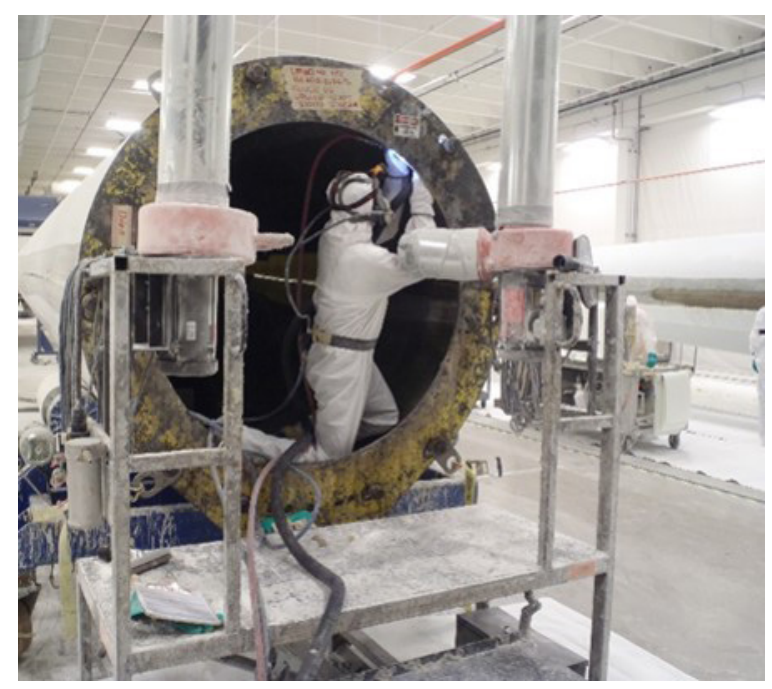

Figure 11. Employee wearing a supplied air respirator performing inside blade cut and trim work using a grinder equipped with local exhaust ventilation. Photo by NIOSH. 


\section{Ventilation}

Table 4 contains the air velocity measurements taken at the exhaust hose inlets of dust generating power tools. In finding the proper guideline against which to compare these measurements, we classified the dust as "average industrial dust" or "grinding dust." With the exception of one angle grinder's hose, all exhaust lines exceeded the minimum recommendations of ACGIH. However, we observed that local exhaust and general exhaust ventilation performance varied at times. For example, a local exhaust hose attached to a sander in finishing and assembly clogged and the employee using it was overexposed to dust that day (see Table 3). Two rooftop air handlers serving blade molding rooms in Building 1 stopped working for approximately 2 hours one day. During the medical evaluation when gel coating and blade gluing were going on, we smelled strong solvent odors in Building 1 nonproduction areas such as the main building entry, bathrooms, and canteen. This indicated the degree of positive air pressurization in nonproduction areas was insufficient at that time.

Table 4. Air velocities in power tool exhaust hoses

\begin{tabular}{llcc}
\hline Location & Tool type & $\begin{array}{c}\text { ACGIH minimum } \\
\text { recommended duct } \\
\text { velocity (feet/min) }\end{array}$ & $\begin{array}{c}\text { Measured duct } \\
\text { velocity (feet/min) }\end{array}$ \\
\hline Finishing and assembly & Orbital sander & $3,500-4,000$ & 7,500 \\
Finishing and assembly & Orbital sander & $3,500-4,000$ & 8,000 \\
Finishing and assembly & Orbital sander & $3,500-4,000$ & 9,000 \\
Finishing and assembly & Orbital sander & $3,500-4,000$ & 7,800 \\
Finishing and assembly & Orbital sander & $3,500-4,000$ & 6,500 \\
Blade cut and trim & Angle grinder & $3,500-4,000$ & 3,500 \\
Blade cut and trim & Angle grinder & $3,500-4,000$ & 6,100 \\
Blade cut and trim & Angle grinder & $3,500-4,000$ & 4,000 \\
Blade cut and trim & Angle grinder & $3,500-4,000$ & 2,800 \\
Blade cut and trim & Angle grinder & $3,500-4,000$ & 4,500 \\
Blade cut and trim & Angle grinder & $3,500-4,000$ & 6,000 \\
\hline
\end{tabular}

\section{Other Airborne Exposure-Related Observations}

We observed several opportunities to reduce potential dust exposures in finishing and assembly and cut and trim areas. Employees regularly used compressed air to blow off dust from their clothing and equipment. This practice can increase their dust exposure especially when done after they have removed their respirator. Some large floor fans were close to the general building exhaust ventilation grilles, but were blowing in the opposite direction the exhaust was trying to pull air contaminants. This setup can decrease the capture efficiency of the exhaust system in that area. Further, some employees used a broom to sweep dust off blades instead of vacuuming the dust with a high efficiency particulate air vacuum. During layup work on the inside of the blade in blade cut and trim, two blowers supplied air 
contaminated with styrene from the adjacent work area to the interior of the blade.

We noticed inconsistent employee adherence to key elements of the respiratory protection program. In finishing and assembly, employees stored elastomeric air purifying respirators in unsealed bags after use without first cleaning them. Employees placed the respirators in the storage bin in piles in a way that could deform the facepieces. Further, employees did not always wear required respiratory protection when walking through blade molding rooms when the blue warning light was on during and soon after gel coating. These factors reduce the overall protection provided by the respirators.

\section{Informal Medical Interviews}

We interviewed 20 employees about their work and health history. Employees noted occasional odors from styrene-containing materials and dust generation. In general, employees indicated that conditions had improved over time, citing the introduction of the lower-styrene gel coat and PPE. Some reported mucous membrane and skin irritation from workplace exposures, but few of the interviewed employees noted chronic health problems that they attributed to work.

\section{Medical Survey Participant Demographics}

Overall, 355 employees participated in at least one portion of the medical survey. Information provided by the plant indicated that 512 employees were currently employed at the time of the survey, with 26 on vacation or sick leave, meaning that $73 \%$ of the available workforce participated. One employee declined to participate in the questionnaire, so we omitted them from analyses that included questionnaire responses. A total of 352 employees took the vision tests, 352 attempted FeNO testing (341 had an interpretable result), and 343 underwent spirometry ( 47 were given a bronchodilator). Urine samples were turned in by 322 employees, or $91 \%$ of participants. The workforce was largely young, white, and male, with short tenures, and had a high proportion of current and former smokers (Table 5).

To understand possible prior exposures, we asked employees about their work in other industries. Twenty-five employees had worked in the auto body industry, 9 in reinforced plastics, and 57 with fiberglass, generally for an average of 5 years or less (data not shown). 
Table 5. Characteristics of medical survey participants $(\mathrm{n}=354)$

\begin{tabular}{lc}
\hline Characteristic & Value \\
\hline Age, years, mean (range) & $37.5(19-65)$ \\
$\quad$ Male, $\mathrm{n}(\%)$ & $267(75.4)$ \\
Race, $\mathrm{n}(\%)$ & $263(74.3)$ \\
$\quad$ White & $46(13.0)$ \\
Black & $20(5.7)$ \\
American Indian or & \\
Alaska Native & $4(1.1)$ \\
Other & $14(4.0)$ \\
More than one race & $7(2.0)$ \\
$\quad$ Missing & \\
Smoking status, $\mathrm{n}(\%)$ & $142(40.1)$ \\
$\quad$ Current & $78(22)$ \\
$\quad$ Former & $134(37.9)$ \\
$\quad$ Never & $4.8,5.5(<1-22.7)$ \\
Tenure, years, mean, & \\
median (range) & \\
Current styrene exposure, mg/g & $69.6,53.6(0.77-941)$ \\
creatinine mean, median (range) & \\
\hline
\end{tabular}

\section{Medical Survey Outcomes}

Over half the workforce reported using a respirator of some kind during their regular job (Table 6). About a third of employees said they wore a half-mask air purifying respirator while another third said they wore a full facepiece air purifying respirator. Half-mask and full facepiece air purifying respirators used at the plant had organic vapor cartridges, some with removable N95 particulate filter covers. In employees classified as being highly exposed to styrene (current styrene exposure equal to or above the median), 77\% reported they wore a respirator, again mostly half-mask or full facepiece air purifying respirators. In employees who worked in dusty jobs, $92.5 \%$ of employees reported they wore a respirator, with a similar breakdown among respirator types. 
Table 6. Self-reported respirator use at the plant

\begin{tabular}{lccc}
\hline & $\begin{array}{c}\text { Overall } \\
(\mathrm{n}=354) \\
\mathrm{n}(\%)\end{array}$ & $\begin{array}{c}\text { High styrene exposure* } \\
(\mathrm{n}=161) \\
\mathrm{n}(\%)\end{array}$ & $\begin{array}{c}\text { High dust exposure } \\
(\mathrm{n}=120) \\
\mathrm{n}(\%)\end{array}$ \\
\hline Respirator use & $209(59.0)$ & $124(77.0)$ & $111(92.5)$ \\
Type of respirator & & & \\
N95 filtering facepiece & $13(3.7)$ & $8(5.0)$ & $7(5.8)$ \\
Half-mask air purifying & $120(33.9)$ & $66(41.0)$ & $65(54.2)$ \\
Full facepiece air purifying & $109(30.8)$ & $71(44.1)$ & $68(56.7)$ \\
Supplied air, full facepiece & $8(2.3)$ & $5(3.1)$ & $6(5.0)$ \\
\hline
\end{tabular}

${ }^{*}$ Defined as current styrene exposure $\geq$ median

†Defined as dust group 1 ("job generates dust")

$\ddagger$ The same individual may use multiple respirators; some individuals may be in both high styrene and high dust categories.

Figure 12 displays the number of employees who reported certain symptoms (black bars). To the right of these bars, the number who identified the symptom as work related (defined as symptom being better on days off from work or on vacation) are in white and the number who identified the symptom as having started after beginning work at the plant are shown in hatch-patterned boxes. When there are no second and third bars, these questions did not have work-related information or date of diagnosis available. Findings of note include that 98 employees $(27.7 \%$ of the workforce) identified symptoms consistent with a diagnosis of asthma (asthma-like symptoms). Additionally, 79 employees (22.3\%) reported wheezing, of whom $34.2 \%$ stated their symptoms improved away from work, and $76 \%$ stated the wheezing started after beginning work at the plant. A total of 85 employees $(24.0 \%)$ reported rash. Out of 24 employees with cough who could identify something that aggravated their cough, 17 identified dust and four identified styrene. Over half (55.3\%) of employees with rash described a work-related rash, and almost half of those with cough (46.5\%) and eye symptoms (41.7\%) stated that these symptoms were work-related. Out of 65 who identified a cause at all, 54 people named fiberglass or dust as something that aggravated their rash. 


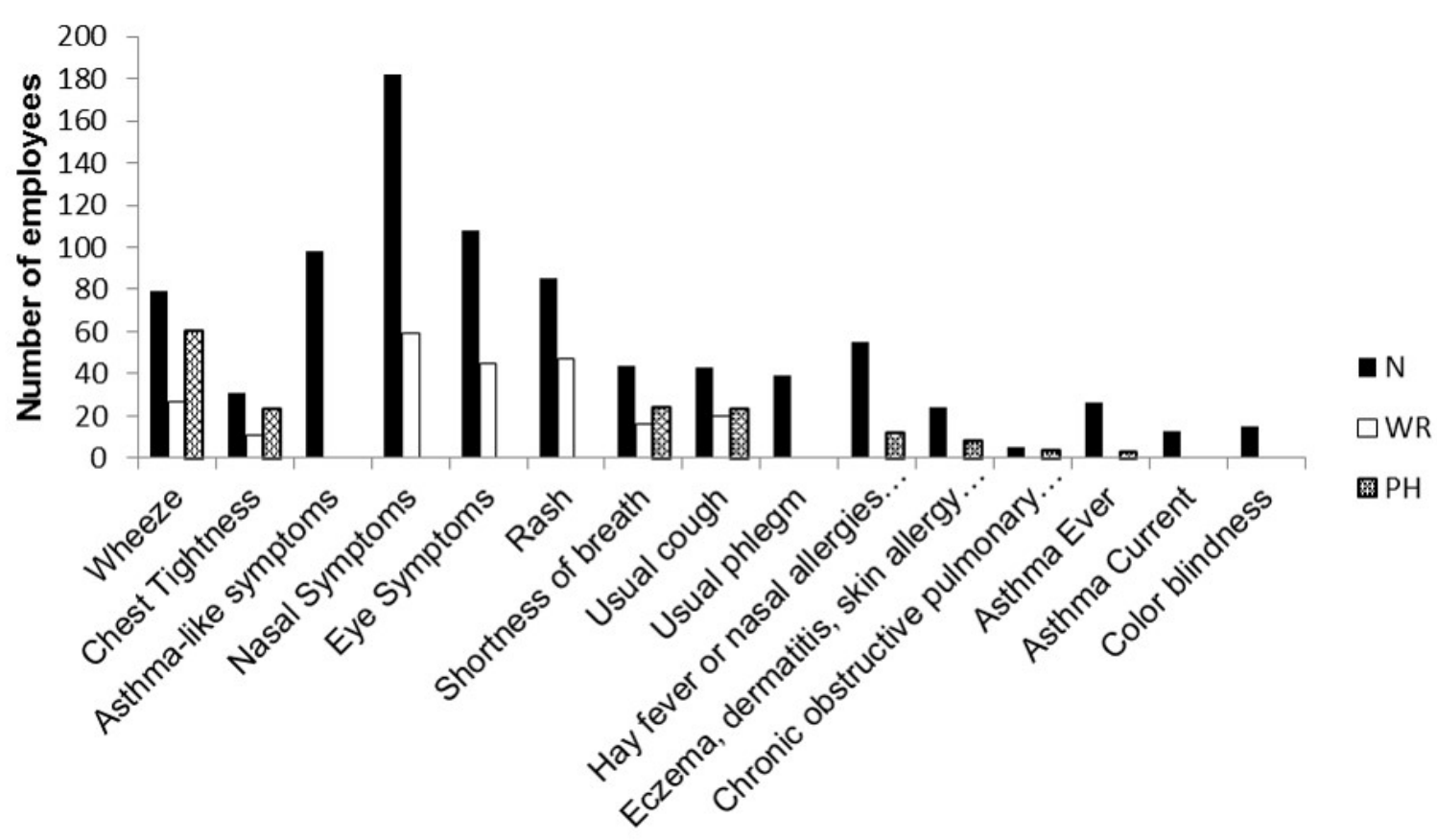

Figure 12. Symptoms and work-relatedness. $\mathrm{N}=$ total number, $\mathrm{WR}=$ work-related, $\mathrm{PH}=$ post hire answering yes.

Table 7 compares the prevalence of symptoms in the plant to those reported in NHANES III (which represents the general U.S. population prevalence) using SMRs. All questions included in this table used similar wording and time frames to NHANES questions. This shows that the prevalences of wheeze, nasal symptoms, asthma (current and ever), and chronic bronchitis in the workforce were similar to the adjusted population prevalences. Shortness of breath, usual cough, usual phlegm, and eye symptoms were less prevalent in the employees.

Table 7. Comparisons of symptoms and self-reported diagnoses among medical survey participants to U.S. adult population (NHANES III) $(\mathrm{N}=354)$

\begin{tabular}{lcccc}
\hline Symptom or diagnosis & Number observed & Number expected & SMR & $\begin{array}{c}\text { 95\% confidence } \\
\text { interval }\end{array}$ \\
\hline Wheeze & 79 & 66.6 & 1.18 & $0.95-1.48$ \\
Nasal symptoms & 181 & 192 & 0.94 & $0.81-1.09$ \\
Eye symptoms & 108 & 133.9 & $\mathbf{0 . 8 1}$ & $\mathbf{0 . 6 7 - 0 . 9 7}$ \\
Shortness of breath & 43 & 65.9 & $\mathbf{0 . 6 5}$ & $\mathbf{0 . 4 8 - 0 . 8 8}$ \\
Cough & 23 & 35.4 & $\mathbf{0 . 6 5}$ & $\mathbf{0 . 4 3 - 0 . 9 8}$ \\
Phlegm & 18 & 31.5 & $\mathbf{0 . 5 7}$ & $\mathbf{0 . 3 6 - 0 . 9 5}$ \\
Asthma, ever & 26 & 27.3 & 0.95 & $0.65-1.40$ \\
Asthma, current & 13 & 16.0 & 0.81 & $0.47-1.39$ \\
Chronic bronchitis, ever & 10 & 17.1 & 0.59 & $0.32-1.08$ \\
\hline
\end{tabular}

Statistically significant SMRs and confidence intervals are in bold. Adjusted for smoking, race, sex, and age ( $\geq 40$ years, $<40$ years). 
Table 8 shows the results of spirometry and FeNO testing in the employees. Of the employees who participated, 47 (13.7\%) had an abnormal spirometry result. The mean percent predicted values for $\mathrm{FEV}_{1}(99.9 \%)$ and FVC (102.5\%) were normal. Forty-seven employees were given a bronchodilator, but these employees were not the same as the 47 employees with an abnormal result. Some employees with an abnormal result declined to take a bronchodilator or had a contraindication, while some employees with a normal result, but a history of asthma or other respiratory disease, were given bronchodilators. Overall, eight (17\%) employees who took the bronchodilator were classified as having reversible obstructive airways disease. Of the 28 employees with obstruction, 24 were given a bronchodilator, and $5(20.8 \%)$ had a reversible test. The mean percent change in $\mathrm{FEV}_{1}$ with bronchodilator was $6.3 \%$ overall, and $7.8 \%$ among employees with obstruction.

Table 8. Results of lung function testing in medical participants

\begin{tabular}{|c|c|}
\hline \multicolumn{2}{|l|}{ Spirometry $(n=343)$} \\
\hline Obstruction, n (\%) & $28(8.2)$ \\
\hline Restriction, n (\%) & $16(4.7)$ \\
\hline Mixed, n (\%) & $3(0.9)$ \\
\hline Any abnormality, $\mathrm{n}(\%)^{*}$ & $47(13.7)$ \\
\hline $\mathrm{FEV}_{1} \%$ predicted, mean (range) & $99.9(46.7-128.8)$ \\
\hline FVC \% predicted, mean (range) & $102.5(71.2-157.6)$ \\
\hline $\mathrm{FEV}_{1} / \mathrm{FVC} \%$, mean (range) & $79.2(46.3-99.0)$ \\
\hline \multicolumn{2}{|l|}{ Bronchodilator $(n=47)$} \\
\hline$\%$ change in $\mathrm{FEV}_{1}$, mean (range) & $6.3(-9.4-28.6)$ \\
\hline Reversible, n (\%) & $8(17)$ \\
\hline \multicolumn{2}{|l|}{ FeNO $(n=341)$} \\
\hline FeNO result ppb, mean (range) & $13.5(3.53-65)$ \\
\hline Abnormal FeNO (> $50 \mathrm{ppb}) \mathrm{n}(\%)$ & $3(0.9)$ \\
\hline FeNO > 25 ppb n (\%) & $30(8.8)$ \\
\hline
\end{tabular}

${ }^{*}$ Any abnormality includes obstruction, restriction, and mixed pattern

The average FeNO result was $13.5 \mathrm{ppb}$. Three employees were classified as abnormal (FeNO > $50 \mathrm{ppb}$ ); an additional 27 employees had a FeNO between 25 and $50 \mathrm{ppb}$. Analysis showed that the FeNO was depressed in current smokers, those who smoked in the last hour, and by steroid use in the last 2 days. Additionally, the consumption of nitrate-rich foods in the last 2 hours had a small depressive effect, which was unexpected. Self-reported exercise in the last hour did not affect the results. FeNO levels were higher in those with a respiratory illness in the last 7 days (data not shown).

Color vision, as described above, was classified as normal, protan, deutan, tritan, or unknown (Table 9). Fifteen employees $(4.2 \%)$ had reported previously diagnosed color blindness, but four of these employees tested as normal. The prevalence of protan color blindness was 
elevated (SMR 1.5), and the prevalence of deutan was decreased (SMR 0.6), though these were not significant. For women, we did not expect to see either protan or deutan color blindness, and we did not. Tritan color blindness is rare, and the expected numbers were less than one for men and women. Yet seven men and three women had this deficiency; thus, the prevalence of tritan color blindness in this workforce is elevated compared to the prevalence in the general population. Twenty-eight people ( 24 men, four women) were classified as having an unknown abnormality. In total, 56 employees $(15.8 \%)$ had an abnormal color vision test. In men, the SMR was 2.3, indicating that the prevalence of color blindness in men was greater than twice that expected from congenital color vision abnormalities. Seven women in total were color blind, with an SMR of 16.6, indicating the prevalence of color blindness in women was more than 16 times greater than expected from congenital color abnormalities.

Table 9. Color vision abnormalities in medical testing participants $(n=352)$

\begin{tabular}{lcccc}
\hline & Observed, $\mathrm{n}(\%)$ & Expected $^{*}, \mathrm{n}(\%)$ & SMR & $\begin{array}{c}95 \% \text { confidence } \\
\text { interval }\end{array}$ \\
\hline $\begin{array}{l}\text { Protan } \\
\text { Male }\end{array}$ & $8(3.0)$ & $5.4(2.0)$ & 1.5 & $0.64-2.9$ \\
$\quad \begin{array}{l}\text { Female } \\
\text { Deutan }\end{array}$ & 0 & $0.02(0.02)$ & $\dagger$ & $\dagger$ \\
$\quad$ Male & $10(3.7)$ & $17.5(6.5)$ & 0.6 & $0.27-1.1$ \\
$\quad$ Female & 0 & $0.3(0.4)$ & $\dagger$ & $\dagger$ \\
Tritan & & & & \\
$\quad$ Male & $7(2.7)$ & $0.03(0.01)$ & $\mathbf{2 7 0}$ & $\mathbf{1 0 5 - 5 3 6}$ \\
Female & $3(3.6)$ & $0.01(0.01)$ & $\mathbf{3 6 0}$ & $\mathbf{7 3 - 1 0 3 1}$ \\
Any abnormality $\ddagger$ & & & & $\mathbf{1 . 7 - 3 . 0}$ \\
$\quad$ Male & $49(18.3)$ & $21.5(8)$ & $\mathbf{2 . 3}$ & $\mathbf{6 . 6 - 3 4}$ \\
$\quad$ Female & $7(8.3)$ & $0.43(0.5)$ & $\mathbf{1 6 . 6}$ & \\
\hline
\end{tabular}

Total males tested: 268 ; total females tested: 84

Statistically significant SMRs (based on percentages) and confidence intervals are in bold.

*All expected percentages taken from an approximate estimate of overall congenital color vision abnormalities in Kalloniatis and Luu 2007.

†Unable to calculate because number observed was zero.

$\ddagger$ Any abnormality defined as having a protan, deutan, tritan, or unknown color vision abnormality.

\section{Job Location}

Employees primarily assigned to different areas differed by job tasks, exposures, respiratory protection, and tenure. Employees in Building 2, where post-molding tasks and web production take place, had the highest percent of respirator use $(79.1 \%)$, followed closely by those in Building 1 (71.4\%). In those who worked "all over," one-third wore respirators, and in office or outdoor employees, $12.5 \%$. We compared exposures to styrene, based on 
urinary styrene metabolite levels, between these different work areas. The mean current styrene exposure was higher for employees working in Building 1 than elsewhere (Table 10). Yet when the cumulative styrene exposures were compared, the mean cumulative styrene exposure for employees working in Building 1 was lower than the mean cumulative styrene exposure elsewhere. To further explore this we looked at tenure and the location of new hires. Mean tenure was 3.9 years in Building 1, but 5.9 years outside of it. Additionally, $50 \%$ of employees hired before October 1, 2012, worked in Building 1 at the time of the survey, but $76 \%$ of those hired after that date worked in Building 1 (Table 6).

Table 10. Building 1 building characteristics

\begin{tabular}{lcc}
\hline & $\begin{array}{c}\text { Works in } \\
\text { Building 1 } \\
(n=189)\end{array}$ & $\begin{array}{c}\text { Does not work } \\
\text { in Building 1 } \\
(\mathrm{n}=165)\end{array}$ \\
\hline $\begin{array}{l}\text { Mean current styrene } \\
\text { exposure }\end{array}$ & $\begin{array}{l}81.8 \mathrm{mg} / \mathrm{g} \\
\text { creatinine }\end{array}$ & $\begin{array}{c}55.1 \mathrm{mg} / \mathrm{g} \\
\text { creatinine }\end{array}$ \\
$\begin{array}{l}\text { Mean cumulative styrene } \\
\text { exposure }\end{array}$ & 4303.9 & 5820.2 \\
$\begin{array}{l}\text { Hired October 1, 2012, or } \\
\text { later }\end{array}$ & $76 \%$ & $24 \%$ \\
$\begin{array}{l}\text { Hired before } \\
\text { October 1, 2012 } \\
\text { Mean tenure }\end{array}$ & $50 \%$ & $50 \%$ \\
\hline
\end{tabular}

"Does not work in Building 1" includes employees in

Building 2, offices, outdoors, and those who work all over.

Table 11. Selected symptoms in Building 1 vs office/outdoor employees

\begin{tabular}{lccc}
\hline Symptom & $\begin{array}{c}\text { Prevalence, } \\
\mathrm{n}(\%)^{*}\end{array}$ & $\begin{array}{c}\text { Odds } \\
\text { ratio }\end{array}$ & $\begin{array}{c}95 \% \\
\text { confidence } \\
\text { interval }\end{array}$ \\
\hline Shortness of breath & $31(16.4)$ & $2.9 \dagger$ & $0.9-9.0$ \\
Cough (usual) & $21(11.1)$ & 2.35 & $0.7-8.6$ \\
Phlegm (usual) & $21(11.1)$ & 2.9 & $0.8-11.2$ \\
Chest tightness in last & $21(11.1)$ & 3.0 & $0.7-13.5$ \\
12 months & & & \\
Asthma-like symptoms & $54(28.6)$ & 1.7 & $0.8-3.5$ \\
\hline
\end{tabular}

*Prevalence in Building 1

†Borderline significant

The data also revealed that certain symptoms and health outcomes were more common in some areas. Looking at the unadjusted prevalence of symptoms by work area indicated that several symptoms might be more prevalent among employees working in Building 
1 compared to the minimally exposed employees in offices or outdoors (data not shown). Those in Building 2 and the "all over" group were not included in this analysis because their exposures may be higher, similar to Building 1 employees. Logistic regression indicated odds ratios of 1.7-3 for asthma-like symptoms, shortness of breath, usual cough, usual phlegm, and chest tightness when comparing the ratio of the odds of the symptom in in Building 1 workers as compared to the odds of the symptom in employees in the office or outdoors, although none of the odds ratios were statistically significant; for shortness of breath the results reached borderline significance (Table 11).

\section{Current Styrene Exposure}

Styrene exposure, as measured by urinary styrene metabolite levels, varied widely throughout the plant. The mean current styrene exposure level was $69.5 \mathrm{mg} / \mathrm{g}$ creatinine, with a range of $0.77-941 \mathrm{mg} / \mathrm{g}$ creatinine (Table 5). The median was $53.6 \mathrm{mg} / \mathrm{g}$ creatinine. As seen in the quartiles in Table 12, the exposures were not normally distributed; rather the majority of employees had exposures below $100 \mathrm{mg} / \mathrm{g}$ creatinine. The ACGIH recommended maximum is $400 \mathrm{mg} / \mathrm{g}$ creatinine, and only one employee exceeded this (941 mg/g creatinine). The employees with the lowest exposure had MA and PGA levels approximately equal to the median seen in unexposed populations (MA: smokers $420 \pm 357$, nonsmokers $198 \pm 226$; PGA: smokers $330 \pm 425$, nonsmokers $169 \pm 224$, all ng/mL) [Alwis et al. 2012]. PHEMA is rarely seen in unexposed populations, and results indicated exposure at some level for all participants [Alwis et al. 2012]. Table 12 shows all departments grouped by the mean current styrene exposure of their employees into quartiles. Those departments whose average current styrene exposure level was above the mean current styrene exposure level in the plant were assembly, cut and trim, mold maintenance, closing and repairs, blade molding, bushings, emergency repair, finishing, and glass cutting.

Table 12. Departments sorted into quartiles by mean current styrene exposure

\begin{tabular}{cccc}
\hline $\begin{array}{c}\text { Quartile 1 (lowest) } \\
0.77-19.4 \mathrm{mg} / \mathrm{g} \\
\text { creatinine }\end{array}$ & $\begin{array}{c}\text { Quartile 2 } \\
\text { 19.5-53.5 mg/g } \\
\text { creatinine }\end{array}$ & $\begin{array}{c}\text { Quartile 3 } \\
53.6-94.4 \mathrm{mg} / \mathrm{g} \\
\text { creatinine }\end{array}$ & $\begin{array}{c}\text { Quartile 4 (highest) } \\
94.5-941 \mathrm{mg} / \mathrm{g} \\
\text { creatinine }\end{array}$ \\
\hline $\begin{array}{c}\text { Regional sales } \\
\text { Receiving/Shipping } \\
\text { Health safety } \\
\text { environment }\end{array}$ & $\begin{array}{c}\text { Netting/Balsa } \\
\text { Gebs }\end{array}$ & $\begin{array}{c}\text { Closing and repairs } \\
\text { Blade molding }\end{array}$ & $\begin{array}{c}\text { Assembly } \\
\text { Cut and trim* }\end{array}$ \\
$\begin{array}{c}\text { Quality control } \\
\text { Human resources }\end{array}$ & Bushings & Mold maintenance \\
Production admin & Facilities & Emergency repair & - \\
Automation & Office & Finishing & - \\
$\begin{array}{c}\text { Production technology } \\
\text { Production equipment }\end{array}$ & - & Glass cutting & - \\
maintenance & - & - & - \\
Materials & - & - & - \\
\hline
\end{tabular}

${ }^{*}$ Includes both blade and web 
Table 13 shows the odds of symptoms in employees with current styrene exposure equal to or above the median $(53.6 \mathrm{mg} / \mathrm{g}$ creatinine) versus employees with current styrene exposure below the median. Only chest tightness in the last 12 months was significant, with the odds of chest tightness 2.9 times higher in the more highly exposed employees than in the less exposed (below median) employees.

Table 13. Prevalence and odds ratios of symptoms by current styrene exposure level equal to or above the median current styrene exposure compared to those below it

\begin{tabular}{lccc}
\hline Symptom or diagnosis & Prevalence, $\mathrm{n}(\%)^{*}$ & Odds ratio & 95\% confidence interval \\
\hline Wheeze & $39(24.2)$ & 1.1 & $0.7-2.0$ \\
Nasal symptoms & $77(47.8)$ & 0.7 & $0.5-1.2$ \\
Eye symptoms & $52(32.3)$ & 1.1 & $0.7-1.7$ \\
Shortness of breath & $22(13.6)$ & 1.2 & $0.6-2.4$ \\
Asthma-like symptoms & $52(32.3)$ & 1.4 & $0.9-2.3$ \\
Cough & $20(12.4)$ & 0.9 & $0.5-1.9$ \\
Phlegm & $19(11.8)$ & 1.1 & $0.6-2.3$ \\
Chest tightness & $21(13.0)$ & 2.9 & $1.2-6.7$ \\
Hay fever, ever & $22(13.7)$ & 0.9 & $0.5-1.6$ \\
Asthma, ever & $7(4.4)$ & 0.5 & $0.2-1.2$ \\
Asthma, current & $5(3.1)$ & 1.1 & $0.3-4.1$ \\
\hline
\end{tabular}

Bold results are significant.

All variables except nasal and eye symptoms are adjusted for age and smoking.

*Prevalence in employees with current styrene exposure greater than or equal to the median current styrene exposure.

†Odds of those greater than or equal to median current styrene exposure having symptom compared to those below the median.

Visual contrast outcomes at frequencies A, B, C, and D were significantly related to log current styrene exposure in the workforce when corrected for visual acuity, diabetes, glaucoma, macular degeneration, cataracts, age, alcohol in the last 24 hours, and smoking (Table 14). This effect was strongest at frequency $\mathrm{C}$ (6 cycles per degree); a 1\% increase in the current styrene exposure led to a decrease of 0.049 in the contrast score at this level (using Formula 2) [Cornell Statistical Consulting Unit 2012]:

$$
\text { Effect estimate }=\text { B-estimate } * \ln (101 / 100) \quad(\text { Formula } 2)
$$

The B-estimate is a slope relating the contrast score and log of styrene exposure given by the linear regression model; it is converted to an effect for the unlogged styrene exposure variables using Formula 2, giving our effect estimate for a $1 \%$ increase in the exposure. To make this more meaningful, we calculated what the change in contrast would be if exposure increased from the 2.5th to 97.5th percentile [Cornell Statistical Consulting Unit 2012], or from 1.8 to $242.0 \mathrm{mg} / \mathrm{g}$ creatinine. Overall, an increase in current styrene exposure from the 2.5th percentile to the 97.5 th percentile would lead to a decrease of 22.1 in the contrast score 
at frequency C. Frequencies A, B, and D show smaller decreases with the same increase in current styrene exposure. Frequency E also shows a decline of 0.015 for every $1 \%$ increase in current styrene exposure, but this trend is of borderline significance. Of the adjustments, only age and visual acuity were significant in the model; the others had minimal effect. Redoing the models without these potential confounders did not significantly change the results.

Table 14. Visual contrast and log current styrene exposure level

\begin{tabular}{lcccc}
\hline $\begin{array}{l}\text { Frequency, } \\
\text { (cycles per } \\
\text { degree) }\end{array}$ & $P$ value & B-estimate & Effect estimate* & $\begin{array}{c}\text { Change in outcome with } \\
\text { current styrene exposure } \\
\text { level change from }\end{array}$ \\
\hline A (1.5) & 0.04 & -1.96 & -0.020 & -8.8 \\
B (3) & 0.03 & -3.50 & -0.034 & -15.6 \\
C (6) & $<0.01$ & -4.93 & -0.049 & -22.1 \\
D (12) & 0.04 & -2.96 & -0.030 & -13.2 \\
E (18) & 0.06 & -1.50 & -0.015 & -6.7 \\
\hline
\end{tabular}

Adjusted for age, smoking status, glaucoma, cataracts, macular degeneration, alcoholic drinks last 24 hours, and visual acuity (of which only age and acuity were significant).

Bolded values are significant.

*Per $1 \%$ change in current styrene exposure level

Other medical outcomes did not appear to be related to our measures of current styrene exposure. Color vision (using color index, kind of abnormality, and grouped abnormality) was not related to $\log$ current styrene exposure or the logs of the individual metabolites. In regression models adjusted for age and visual acuity, participants with tritan or unknown category colorblindness had lower visual contrast sensitivity at the $\mathrm{C}$ and $\mathrm{B}$ frequencies than participants with no colorblindness $(\mathrm{p}<0.05)$. Spirometry outcomes, including obstruction, restriction, mixed, and any abnormal test, did not correlate with current styrene exposure as measured by log current styrene exposure or the current styrene exposure median. FeNO also was not related to those two exposure variables or the log of any of the individual metabolites.

\section{Cumulative Styrene Exposure}

Cumulative styrene exposure, as measured by the log of the cumulative styrene exposure score, was significantly associated with wheeze (odds ratio 1.3), nasal symptoms (odds ratio 1.2), eye symptoms (odds ratio 1.2), and asthma-like symptoms (odds ratio 1.2) (Table 15). 
Table 15. Odds of symptoms by log cumulative styrene exposure

\begin{tabular}{lcc}
\hline Symptom or diagnosis & Odds ratio* $^{*}$ & 95\% confidence interval \\
\hline Wheeze & $\mathbf{1 . 3}$ & $\mathbf{1 . 1 - 1 . 5}$ \\
Nasal symptoms & $\mathbf{1 . 2}$ & $\mathbf{1 . 1 - 1 . 4}$ \\
Eye symptoms & $\mathbf{1 . 2}$ & $\mathbf{1 . 1 - 1 . 4}$ \\
Shortness of breath & 1.1 & $0.9-1.3$ \\
Asthma-like symptoms & 1.2 & $\mathbf{1 . 0 - 1 . 4 \dagger}$ \\
Cough usual & 1.0 & $0.8-1.3$ \\
Phlegm usual & 1.1 & $0.9-1.3$ \\
Chest tightness & 1.1 & $0.9-1.4$ \\
Hay fever, ever & 1.0 & $0.8-1.2$ \\
Asthma, ever & 1.0 & $0.8-1.3$ \\
Asthma, current & 1.2 & $0.8-1.8$ \\
Chronic bronchitis, ever & 1.5 & $0.9-2.5$ \\
\hline All
\end{tabular}

All variables except nasal and eye symptoms are adjusted for age and smoking status. Bold results are significant.

*Because the models were run using the natural log of the cumulative exposure estimate, these ORs represent the change in odds of each symptom with a 2.7-fold change in the untransformed cumulative exposure.

†For asthma-like symptoms, the P-value was $<0.05$. The $95 \%$ confidence interval includes 1.0 due to rounding.

Cumulative styrene also correlated with spirometry outcomes (Table 16). Using the log of the cumulative styrene exposure, we found that a $1 \%$ increase in the cumulative styrene exposure was associated with a drop of 0.026 in the percent predicted forced expiratory flow 25\%-75\% (FEF25-75), 0.006 in the ratio of $\mathrm{FEV}_{1} / \mathrm{FVC}$, and 0.008 in the percent predicted $\mathrm{FEV}_{1}$. The drops in both percent predicted FEF25-75 and $\mathrm{FEV}_{1} / \mathrm{FVC}$ were significant; the drop in percent predicted $\mathrm{FEV}_{1}$ was borderline. Drops with an increase in cumulative exposure from the 2.5th percentile to the 97.5th percentile were 3.5 units for FEV/FVC and 15.6 for FEF 25-75. The FVC did not appear to be correlated with cumulative styrene exposure.

FeNO also correlated with log cumulative exposure (Table 16). In this case, the FeNO decreased by 0.009 for every $1 \%$ increase in the cumulative styrene exposure when corrected for smoking status, respiratory illness, sex, age, and consumption of nitrate-rich foods. We repeated the analysis looking at nonsmokers only, and found a similar trend (data not shown). Comparing FeNO to the log of individual metabolites confirmed this effect (data not shown). 
Table 16. Spirometry outcomes by log cumulative styrene exposure

\begin{tabular}{|c|c|c|c|c|}
\hline Spirometry measure & Adjusted for & $\begin{array}{c}\text { Effect } \\
\text { estimate, per } \\
1 \% \text { change } \\
\text { in exposure }\end{array}$ & $P$ value & $\begin{array}{l}\text { Change in outcome } \\
\text { with cumulative } \\
\text { styrene exposure } \\
\text { change from } 2.5 \text { th } \\
\text { to } 97.5 \text { th percentile }\end{array}$ \\
\hline $\mathrm{FEV}_{1} / \mathrm{FVC}$ & $\begin{array}{c}\text { Age, smoking status, } \\
\text { BMI }\end{array}$ & -0.006 & 0.015 & -3.5 \\
\hline $\begin{array}{l}\text { Percent predicted } \\
\text { FEV }_{1}\end{array}$ & Smoking status, BMI & -0.008 & 0.079 & -5.0 \\
\hline $\begin{array}{l}\text { Percent predicted } \\
\text { FEF25-75 }\end{array}$ & Smoking status, BMI & -0.026 & 0.011 & -15.6 \\
\hline Percent predicted FVC & Smoking status, BMI & -0.001 & 0.7 & -0.93 \\
\hline $\begin{array}{l}\text { Fraction of exhaled } \\
\text { nitric oxide }\end{array}$ & $\begin{array}{l}\text { Smoking status, } \\
\text { respiratory illness, } \\
\text { consumption of nitrate- } \\
\text { rich foods, gender, age }\end{array}$ & -0.009 & 0.0013 & -5.54 \\
\hline
\end{tabular}

Color vision did not relate to cumulative styrene exposure using CCI, color angle, or the type of color blindness, though the trend indicated high styrene might be associated with less color blindness. In the grouped analysis, higher cumulative styrene exposure was associated with less unknown/tritan color blindness (odds ratio 0.7; 95\% confidence interval 0.6-0.9); this seemed to be driven by the employees with the unknown type of color blindness rather than tritan. Color vision also did not show a relationship to the highest exposure job that each individual had held.

\section{Discussion}

\section{Air Sampling and Ventilation}

A prior NIOSH evaluation at this facility documented styrene and dust overexposures that the company began addressing through product substitution, task elimination, improved general ventilation and local exhaust ventilation, and respiratory protection [Hammond et al. 2011]. The results we obtained during the current evaluation indicate those changes lowered employee exposures to dust and styrene. However, overexposures to both dust and styrene were found in Building 2, especially in blade cut and trim. Despite local exhaust ventilation hose velocities mostly meeting or exceeding best practice guidelines, employees were overexposed to dust in several areas. Our observations indicate this is from inefficient dust capture at the point of dust generation and not due to insufficient exhaust transport velocities. For example, although all angle grinders had a shroud around the grinding wheel, the grinding wheel could not always be placed flat against the blade surface for best dust capture because of the blade's curved contour. Dust exposures in blade cut and trim must be reduced by more than $80 \%$ to be below the OSHA PEL. In the judgment of NIOSH ventilation engineers, no currently available engineering controls can deliver this level of reduction, so other controls are needed. Opportunities to lower dust exposures for employees not doing 
cut and trim tasks may be more quickly implemented than in cut and trim areas. Examples of controls that can be immediately implemented include vacuuming blades and floors with a high efficiency particulate air vacuum instead of dry sweeping, and eliminating use of compressed air to clean employees' clothes.

We observed that performance of the general ventilation and local exhaust ventilation systems varied. When the effectiveness of these controls is reduced, employee exposures to styrene and dust can increase. This was illustrated by the clogged sander exhaust hose in Building 2, and styrene odor migration into non-production areas in Building 1. These events underscore the importance of good preventative maintenance on and periodic performance monitoring for those systems.

The respirators used throughout the facility would be expected to reduce exposures below the NIOSH, OSHA, and ACGIH limits when used as part of a continuing, effective respiratory protection program. We observed some respirator use practices that would limit the effectiveness of respirator use, for example improperly storing respirators in finishing and assembly and not always wearing respiratory protection in blade molding rooms after gel coating when airborne styrene concentrations are highest.

Much time is spent by employees doing cut and trim work to achieve desired blade performance. However, because existing engineering controls were not adequate to keep exposures to dust and styrene below exposure limits the company should re-evaluate the cut and trim work being done inside the blade. Consideration should be given to whether all grinding work done inside the blades is required for blade performance, rather than aesthetic reasons. If the decision is that it is necessary for performance, then optimizing blade and web mold design and molding processes should be prioritized to reduce the amount of sanding, grinding, and laying up fiberglass. From an occupational health and safety standpoint, exposure generating tasks done primarily for aesthetic reasons present an opportunity for exposure reduction by eliminating the task altogether.

This facility previously eliminated one source of styrene exposure by switching to a styrenefree two-part polymer caulk adhesive to attach the safety platform to each blade. This new adhesive was thought to contain residual amounts of xylene. Our samples detected full-shift personal air concentrations of xylene well below 1 ppm, indicating this was a successful product substitution to lower styrene exposures without causing xylene exposure concerns.

\section{Medical Survey Results}

We found an overall excess of color blindness and associations between styrene exposure (as measured by urine styrene metabolites at the end of shift) and visual contrast deficits, respiratory symptoms, and reduced lung function. Current styrene exposure was associated with decreased visual contrast at medium and low frequencies. Current styrene exposure above the plant median of $69.5 \mathrm{mg} / \mathrm{g}$ creatinine was significantly associated with selfreported chest tightness in the last 12 months. Cumulative styrene exposure was associated with lower lung function; a similar pattern of airflow limitation is seen in obstructive lung disease. Most of the obstruction in this study population was not reversible, indicating it was 
nonasthmatic. These findings indicate adverse neurological and respiratory effects of styrene exposure in this plant and support further exposure reduction and expanded medical surveillance.

The excess of color vision abnormalities in the workforce at large is striking. Available estimates [Kalloniatis and Luu 2007] indicate that approximately $8.0 \%$ of men and $0.5 \%$ of women would be expected to have congenital abnormal color vision. Yet $18 \%$ of men and $8 \%$ of women had an abnormal test. This is over twice the expected amount. Additionally, the estimates were based on Caucasian North American populations, and studies have shown that African Americans, Native Americans, and Asians all have lower levels of color blindness [Birch 2012]. We did not subgroup by race because the groups would have been too small for reliable statistical comparison. The excess is mostly found in the tritan group (10 people) and the unknown group ( 28 people). The unknown group may represent a combination of two abnormalities (likely deutan and tritan) or complete color blindness. Most earlier studies found blue-yellow color abnormalities in workers with styrene exposures higher than those in our study, some of whom did not wear any respiratory protection [Campagna et al. 1995; Castillo et al. 2001; Eguchi et al. 1992; Iregen et al. 2004; Kishi et al. 2001]. Reports in the literature have indicated that acquired deficits in color vision may begin with tritan (blueyellow) and progress through red-green color blindness until an employee is completely color blind [Fox and Boyes 2013].

Studies have indicated some reversibility in color blindness may occur when styrene exposure is decreased [Castillo et al. 2001; Seeber et al. 2009; Triebig et al. 2001], and such reversibility may have affected our results, making it difficult to associate the color blindness with cumulative or current exposure. Between the time of the first NIOSH evaluation at this facility in 2007 [Hammond et al. 2011] and the NIOSH medical testing in 2013, important styrene exposure reduction steps were taken. Several of them include (1) eliminating an entire process where styrene exposures previously were immediately dangerous to life and health (not considering any benefit from the powered air purifying respirators used at the time), (2) reducing the styrene content of the gel coat by approximately half, and (3) replacing the styrene-containing materials used to affix the safety platform in the root of blades with a styrene-free product. Over this same time period, the company also increased (1) the use of respiratory protection among lower-exposed employees (Building 1 employees began wearing air purifying respirators any time gel coating occurs anywhere in their blade molding room), and (2) the level of protection for the highest exposed employees (inside blade cut and trim employees began wearing full-facepiece supplied air respirators).

Other possibilities for why we could not see an exposure-response effect, assuming that one exists, include a lack of statistical power because of the number of people in the study; a larger study might have been able to associate these deficits with exposure. Furthermore, most exposures were clustered in a tight group below the current styrene exposure limit of $400 \mathrm{mg} / \mathrm{g}$ creatinine; in the absence of variation in exposure levels, dose-dependent relationships can be difficult to detect. Another possibility is a modifying effect of some other exposure.

In this assessment, the log of current styrene exposure related to visual contrast outcomes at all frequencies. The effect was strongest at the intermediate frequency of 6 cycles per degree, which supports prior literature on this topic [Castillo et al. 2001]. Though the effect 
at frequency E (18 cycles per degree) was of borderline significance, the effect estimate was similar. In this case, it is likely that we were lacking statistical power to tell the difference between more exposed and less exposed persons, because even those without a deficit in visual contrast are unlikely to score well at this frequency (Figure 4). Contrast vision is important in activities of daily living; for example, mid frequency cycles are crucial for facial recognition [Fox and Boyes 2013]. Good contrast allows people to perceive their environment more clearly; those with decreased contrast are at risk for workplace and car accidents due to decreased vision [Fox and Boyes 2013]. Thus, this loss of contrast vision can have significant effects on workplace safety.

When we examined symptoms in employees exposed to styrene, we found that chest tightness in the past 12 months was nearly three times more common in employees with current styrene exposure greater than or equal to the median than below. The odds of having asthma-like symptoms were also higher in the more highly exposed employees, although not statistically significant. Such findings indicate that although many symptoms appeared less common in the workforce overall, certain subsets of the population are more likely to have symptoms. For current exposure, symptoms associated with asthma, such as chest tightness and asthma-like symptoms, were most common. For employees who had high cumulative exposure to styrene, this was even more pronounced: the odds ratio asthma-like symptoms reached statistical significance, as did wheeze and nasal/eye irritation. These findings support prior literature that indicates styrene may be a respiratory irritant and a cause of occupational asthma [Helal and Elshafy 2012; Moscato et al. 1987].

Concern for lung disease was further reinforced by the association between cumulative styrene exposure and spirometry results. The association with cumulative exposure and not current exposure as estimated at the time of our survey suggests that the effect of styrene exposure is additive over time, rather than immediate. $\mathrm{FEV}_{1} / \mathrm{FVC}$ below the lower limit of normal generally indicates an obstructive lung problem; a decreased ratio that nevertheless remains within the range of normal may represent an early change in the development of obstruction. While some of these employees still may have fallen within the range of normal, the association of increasing cumulative styrene exposure with decreasing $\mathrm{FEV}_{1} / \mathrm{FVC}$ is concerning. The significant impact on FEF25-75 suggests that the small airways are involved [Burgel 2011]. Only 21\% of the employees with obstruction who were given bronchodilators had a positive response, which is consistent with fixed obstructive lung disease, including obliterative bronchiolitis, a disease of the small airways. In a cross-sectional study of adults ages $40-79,36 \%$ of those with obstruction responded to a bronchodilator [Doney et al. 2014], suggesting that the rate of fixed obstruction in our younger study population was higher than expected. Most participants with fixed obstruction were current or former smokers. Nonetheless, the relatively young ages and limited smoking histories make it difficult to attribute these abnormalities solely to smoking.

A link between styrene and obliterative bronchiolitis, a rare irreversible lung disease, was suggested recently by two case series, which described 8 workers employed in the reinforced plastics industry (primarily boatbuilding) who had obliterative bronchiolitis [Chen et al. 2013; Cullinan et al. 2013]. Additionally, a large epidemiologic study described excess mortality from obstructive lung disease in highly exposed, short-term reinforced-plastics 
workers, which would be consistent with obliterative bronchiolitis [Collins et al. 2013; Cummings et al. 2014]. Furthermore, an occupational study in an Egyptian reinforced plastics factory found that styrene exposure correlated with decreased pulmonary function tests, indicating that obstruction, especially mid-flow obstruction, might be a consequence of styrene exposure [Helal and Elshay 2012].

Our results showed that FeNO correlated inversely with cumulative styrene exposure. This was an unexpected result, as we expected higher FeNO levels with increasing exposure, especially in those with symptoms of irritation or asthma. Yet the FeNO results failed to correlate with asthma-like symptoms as well (data not shown). We adjusted for current smoking status, age, sex, respiratory illness, and nitrate-rich foods. We also tried stratifying by smoking status because the prevalence of smoking was so high in this population, but nonsmokers demonstrated a similar relationship between styrene and FeNO.

FeNO is a measure of airway inflammation; in most literature it is thought to measure eosinophilic inflammation (consistent with allergies, asthma, or nonasthmatic eosinophilic bronchitis) and not neutrophilic or other forms [Pala et al. 2011; Quirce et al. 2012]. Indeed, in patients with refractory asthma, low FeNO levels were associated with the presence of neutrophils in the sputum [Tseliou et al. 2010]. Thus, it is possible that our finding of lower FeNO with increasing cumulative styrene exposure reflects the development of neutrophilic (rather than eosinophilic) inflammation in the airways with styrene exposure. Furthermore, though we asked screening questions (including about smoking, food intake, and exercise) in order to control for known confounders, we did not find evidence of confounding. For instance, we noted decreased (rather than the expected increased) FeNO among those who ate nitrate-rich foods, and saw similar mean FeNO among those who had exercised and those who had not (data not shown). Finally, tobacco depresses FeNO, and perhaps styrene, a component of tobacco smoke, does the same; this is unknown at this time.

Overall, many employees described nasal symptoms, chest tightness, wheeze, rash, shortness of breath, and usual cough as work related. In several instances, employees could pinpoint a specific exposure that aggravated their symptoms, usually dust or fiberglass or styrene. The odds of such symptoms were not greater than in the general population; this may reflect the "healthy worker effect." The healthy worker effect describes a phenomenon where employees tend to be healthier than the general public, because employees who are ill leave the workforce, or move to a different job if their current job causes health symptoms. Nevertheless, it is sometimes possible to see increased rates of symptoms or disease in certain subsets of the workforce, for example, in this workplace those exposed to styrene, as discussed above. The healthy worker effect may also play a role in the normal lung tests for the population overall. Working in this industry is a physically demanding job for most production employees; employees with decreased lung function may move to office jobs or to another industry entirely because of difficulty breathing. Finally, the healthy worker effect may have accounted for our finding that higher cumulative styrene exposure was associated with less unknown/tritan color blindness, if styrene-related co-morbidities (such as respiratory health effects) led affected workers to leave the workforce before this crosssectional evaluation was performed. 
We identified departments, based on mean urinary styrene metabolite levels, where the highest exposures occurred: assembly, cut and trim areas, and mold maintenance. We also identified bystander jobs where unanticipated exposure could have occurred. Seventyseven percent of employees exposed to styrene above the plant's median and $92 \%$ in jobs that generate dust reported wearing respirators. This indicates that some employees were presumed unexposed, or exposed below the exposure limit, and thus did not use respirators. For example, blade entry attendants were not required to wear respiratory protection, but they worked nearby employees for whom we measured styrene overexposures (the 'inside' employees). We measured blade entry attendant airborne styrene exposures higher than half the exposure limit, and observed that their work practices (how long they stood physically close to the blade root while high styrene concentrations were generated inside) varied. These factors suggest blade entry attendants may occasionally be overexposed to styrene, could be in need of respiratory protection, and that further evaluation of this possibility is warranted.

\section{Limitations and Strengths}

Limitations of this study include a potential under- or overestimation of current styrene exposure. Though the current recommendation is to collect urine at the end of shifts, as this correlates well with air-styrene levels, to our knowledge this has not been explicitly studied in workplaces with episodic exposures that may have occurred early in the shift, such as sometimes seen in the molding department in this workplace. Additionally, some employees changed jobs or tasks weekly. For example, one week certain molders might come in early to prepare the mold and spray gel-coat. The next week they might be primarily laying balsa wood and fiberglass layers with little styrene exposure. Thus, the measurements on the day of the test may not have represented current exposure beyond the date of the test, which could lead to an overestimation or underestimation of exposure.

Some other important considerations in interpreting these results include the significant changes in exposure over the past several years at the plant, which may have led to underestimation of cumulative styrene exposure. As discussed above, certain high-exposure processes were eliminated, while ventilation and personal protection practices improved for other tasks. Perhaps most significantly, the percent of styrene in the gel-coat was significantly reduced. Though we treated our variable as an indication of relative exposure during work at the plant, in some instances this may have been misleading. Furthermore, the reductions in exposure were not uniform across all jobs, making it difficult to back-extrapolate. Variations in PPE use over time and between employees could also affect this, meaning one person's exposure might have been higher or lower than another employee with the same job history. We were unable to account for this possible effect.

Cumulative styrene exposure estimation depended on job history. Many employees had short tenures with only a few job changes, but because our estimation relied on self-recall, errors may have occurred. As in the case of measuring current styrene exposure, estimating cumulative styrene exposure is complicated if employees change tasks week to week. We tried to account for this variation in tasks within a department or a job title by using averages of all employees in the same position, but over time such individual variations in work patterns could lead to a difference between estimated and actual exposure. Additionally, 
because of the fluctuations in demand for windblades over time, the size of this workforce has varied from as few as 300 employees to over 900 employees in the past few years. Many employees were hired, laid off, and rehired. Much of the rehiring had happened in the months just before the medical survey. We tried to account for this, but periods of time away from the plant could have easily affected this variable; such gaps may leave time for employees to recover from exposures. Additionally, the employees who get rehired may be healthier or less susceptible to the effects of styrene than employees who previously worked at the plant, but were not rehired.

The job location variable was subject to misclassification for several reasons. First, during the questionnaire portion of the evaluation, employees reported job title and typical tasks performed. Some employees reported tasks not generally associated with their reported title (e.g., "grinding the blade" reported by an office employee). This made it difficult to classify these employees into a specific location. Also, job titles and departments were very fluid; employees frequently filled in as needed at a job that might not be their primary job or even changed jobs within their department week to week, leading to further misclassification. These analyses also lacked power because the groups other than Building 1 were relatively small with about 50 people in each.

Another limitation is that participation was uneven across the plant. Reportedly some supervisors were not able to let their employees come to testing, with the result that certain job titles and departments were not included in the styrene analysis or in the testing at all. Additionally, some employees may have had concerns about privacy, because the medical testing was in a large, high-traffic area, and a management representative was frequently present in another part of the room.

Strengths of this study include the large workforce with styrene exposure and excellent participation rate of $73 \%$. Though styrene exposure has been linked to health outcomes previously, most studies have concentrated on visual symptoms or cancer. The few nonneoplastic respiratory studies were largely in the boat-building industry [Cullinan et al. 2013; Helal and Elshafy 2012], so this investigation into styrene exposure in a different industry is a useful addition to the literature.

The use of biological markers to measure exposure is another strength of this study. Because of the wide and varied use of PPE, air styrene measurements alone, while useful to identify high-risk areas and determine the need for PPE, are not as useful as biological markers in trying to link health effects to exposures. We had excellent participation in the biomonitoring facet of testing, and employees were generally able to provide urine at the end of their shift, when styrene metabolite excretion should have been highest. Our finding of associations between styrene biomarkers and health outcomes suggest that styrene may have health effects below previously identified thresholds. Yet it is possible that styrene may be a marker for another source of health effects, or that some of our effects are due to co-exposures to styrene and other workplace chemicals, fiberglass, or dust. As such, overall exposure reduction is prudent. 


\section{Conclusions}

Most production employees were not exposed to airborne styrene or dust above the lowest OELs on the days of our industrial hygiene evaluation, with the exception of employees doing cut and trim tasks. All inside blade cut and trim airborne exposures to dust exceeded the OSHA limit, despite using powered hand tools with local exhaust ventilation that met best practice guidelines. Those who were overexposed to airborne styrene or dust wore a level of respiratory protection adequate to reduce their exposure below the lowest OELs. Elsewhere in the plant however, respirators were not always used when needed and respirators were not always stored away from contamination. These problems will reduce the effectiveness of the respiratory protection.

Almost all employees who provided a urine sample showed current styrene levels below the current recommended limit (400 mg/g creatinine) set by ACGIH. Yet the plant had an excess of color blindness, particularly tritan and unknown types, which are associated with acquired color vision loss. Tritan color blindness in particular is associated with styrene exposure, and there is reason to think that unknown abnormalities may represent a progression of color blindness due to styrene exposure. We could not explain this excess of color blindness with our biological markers of current or cumulative exposure. Additionally, decreased visual contrast correlated with current styrene exposure, and decreased $\mathrm{FEV}_{1} / \mathrm{FVC}$ and FEF25-75 with cumulative exposure. The respiratory health findings demonstrated a link between cumulative styrene exposure and decreased lung function. This pattern of airflow limitation is seen in obstructive lung disease. The odds of certain symptoms, such as wheeze and asthma-like symptoms, were elevated in those with higher cumulative styrene exposures; the odds of chest tightness were elevated in those with higher current styrene exposure. The data suggest that some employees who were presumed to have no exposure to styrene and dust do have such exposures. The association of such health outcomes with biological markers of styrene exposure below the ACGIH recommended limit indicates the limit (400 $\mathrm{mg} / \mathrm{g}$ creatinine, adopted to minimize neurological effects [ACGIH 2016a]) may not be accomplishing the goal of protecting employees from some of the health effects observed during this evaluation. The association of cumulative exposure with our outcomes indicates that there are long-term effects, particularly on respiratory health, in addition to the acute effects on vision. Although the associations we found were between styrene exposure and health effects, it is possible that styrene may be a marker for another source of health effects, or that some of our effects are due to co-exposures to styrene and other workplace chemicals, fiberglass, or dust. As such, overall exposure reduction is prudent.

\section{Recommendations}

On the basis of our findings, we recommend the actions listed below. We encourage the company to use a labor-management health and safety committee or working group to discuss our recommendations and develop an action plan. Those involved in the work can best set priorities and assess the feasibility of our recommendations for the specific situation at the facility. 
Our recommendations are based on an approach known as the hierarchy of controls (Appendix C) This approach groups actions by their likely effectiveness in reducing or removing hazards. In most cases, the preferred approach is to eliminate hazardous materials or processes and install engineering controls to reduce exposure or shield employees. Until such controls are in place, or if they are not effective or feasible, administrative measures and PPE may be needed.

\section{Elimination and Substitution}

Eliminating or substituting hazardous processes or materials reduces hazards and protects employees more effectively than other approaches. Prevention through design, considering elimination or substitution when designing or developing a project, reduces the need for additional controls in the future.

1. Re-engineer the blade molding process, perhaps including changes to mold designs, to eliminate the need for so much work with grinders and laminate especially in blade cut and trim.

2. Evaluate whether further decreases in styrene content is possible for gel-coat, resin, and paint.

\section{Engineering Controls}

Engineering controls reduce employees' exposures by removing the hazard from the process or by placing a barrier between the hazard and the employee. Engineering controls protect employees effectively without placing primary responsibility of implementation on the employee.

1. Use sanding and grinding tools with exhaust ventilation shrouds that conform more closely to the shape of the blade surface to increase the dust collection efficiency.

2. Supply $100 \%$ outdoor air to the inside of blades in blade cut and trim, instead of styrene-containing air from the adjacent indoor environment.

3. Instead of sweeping off dusty blades or using compressed air on employees' clothes, vacuum them off with a high efficiency particulate air filtered vacuum.

\section{Administrative Controls}

The term administrative controls refers to employer-dictated work practices and policies to reduce or prevent hazardous exposures. Their effectiveness depends on employer commitment and employee acceptance. Regular monitoring and reinforcement are necessary to ensure that policies and procedures are followed consistently.

1. Eliminate as much exposure-generating cut and trim work as possible if it is done solely for aesthetic reasons.

2. Inspect piping and hoses associated with grinder and sander exhaust ventilation routinely to make sure no plugging occurs.

3. Begin annual respiratory surveillance for all employees who work anywhere at the plant because of the link between decreased $\mathrm{FEV}_{1} / \mathrm{FVC}$ and cumulative styrene exposure. Include office employees who may be exposed by walking through the 
plant. High quality spirometry is required to look at serial measurements for evidence of excessive decline year to year. NIOSH and OSHA provide information for ensuring high quality spirometry, including information on NIOSH approval of spirometry training courses (http://www.cdc.gov/niosh/topics/spirometry/training.html) and guidance on how to maximize spirometry surveillance resources (https://www.osha. gov/Publications/osha3415.html).

4. Analyze individual and group spirometry data by looking at changes in function over time, which may allow early, presymptomatic, identification of employees with lung disease. A decline in the percent predicted value of $\mathrm{FEV}_{1}$ of greater than $15 \%$ from baseline is considered excessive and should prompt referral to a lung specialist familiar with occupational lung disease [Redlich et al. 2014]. Additionally, look at longitudinal spirometry data by area of the plant to pinpoint areas that may be problematic. Such analysis can be done using software that is currently available. NIOSH has designed a free tool called SPIROLA, available on the NIOSH website (http://www.cdc.gov/niosh/ topics/spirometry/spirola-software.html) [NIOSH 2013] to facilitate this analysis.

5. Consider offering vision testing to employees as part of their yearly health exam because of the high prevalence of color vision deficiencies and the association between decreased contrast vision and current styrene exposure. Also, make sure warning and other safety-related labels/signs within the plant are easy to read for those with these kinds of vision deficiencies. Consider instituting auditory alerts when necessary.

6. Use medical surveillance results to guide the introduction of additional controls as needed.

7. Identify tasks or jobs previously thought to have no exposure to styrene but identified as exposed in our study. Implement appropriate protection for these employees.

8. Evaluate blade cut and trim attendant exposures to styrene to determine whether respiratory protection is needed.

9. Prohibit employees from using compressed air to blow off equipment or their clothing.

10. Periodically monitor ceiling, short-term, and full-shift employee exposures to styrene, and full-shift exposures to dust, including when process changes are made that could affect those exposures.

\section{Personal Protective Equipment}

PPE is the least effective means for controlling hazardous exposures. Proper use of PPE requires a comprehensive program and a high level of employee involvement and commitment. The right PPE must be chosen for each hazard. Supporting programs such as training, change-out schedules, and medical assessment may be needed. PPE should not be the sole method for controlling hazardous exposures. Rather, PPE should be used until effective engineering and administrative controls are in place.

1. Re-evaluate PPE requirements and adherence for employees identified by our medical evaluation as being more highly exposed to styrene, including bystanders such as bushings winding employees and blade cut and trim attendants, and jobs in finishing and assembly, cut and trim, mold maintenance, and closing and repairs. 
2. Ensure respirators are stored in clean, accessible areas. Specifically, make sure that elastomeric facepiece respirators are not stored in ways that can deform the facepiece, possibly altering its fit.

3. Encourage the use of gloves and other skin protection for employees exposed to fiberglass and dust, which were reported by employees to cause rash. 


\section{Appendix A: Tables}

Table A1. Building 1 (blade molding) personal air sample results for styrene, June 11-13, 2013

\begin{tabular}{|c|c|c|c|c|}
\hline Date & Job or activity & $\begin{array}{l}\text { Sample duration } \\
\text { (minutes) }\end{array}$ & $\begin{array}{l}\text { Total volume } \\
\text { (liters) }\end{array}$ & $\begin{array}{c}\text { Concentration } \\
(\mathrm{ppm})\end{array}$ \\
\hline \multirow[t]{10}{*}{ June 11} & Gel coat machine operator & 506 & 25.3 & 2.9 \\
\hline & Gel coat machine operator & 360 & 16.4 & $5.0^{*}$ \\
\hline & Gel coat sprayer & 585 & 29.3 & 5.7 \\
\hline & Gel coat sprayer & 349 & 17.4 & 4.3 \\
\hline & Gel coat sprayer & $197 \dagger$ & 9.9 & 6.9 \\
\hline & Gel coat sprayer & 529 & 26.3 & 6.8 \\
\hline & Gluer & 447 & 22.3 & 8.0 \\
\hline & Molding - other & 484 & 24.2 & 8.1 \\
\hline & Molding - other & 485 & 24.3 & 6.2 \\
\hline & Bushing winding & 575 & 28.8 & 7.7 \\
\hline \multirow[t]{11}{*}{ June 12} & Gel coat machine operator & 569 & 28.5 & 2.6 \\
\hline & Gel coat machine operator & 521 & 26.1 & 4.1 \\
\hline & Gel coat machine operator & 494 & 24.7 & 3.1 \\
\hline & Gel coat sprayer & 567 & 28.5 & 3.1 \\
\hline & Gel coat sprayer & 488 & 24.4 & 3.4 \\
\hline & Gel coat sprayer & 478 & 23.9 & 2.0 \\
\hline & Infuser & 495 & 24.8 & 1.9 \\
\hline & Infuser & 486 & 22.6 & 1.7 \\
\hline & Closing and glass prep & $312 \ddagger$ & 15.6 & $17 \S$ \\
\hline & Mold close/repairs & 493 & 24.7 & 4.8 \\
\hline & Bushing winding & $282 \S$ & 14.1 & 7.7 \\
\hline \multirow[t]{11}{*}{ June 13} & Gel coat machine operator & 612 & 30.6 & 2.8 \\
\hline & Gel coat machine operator & 579 & 29 & 3.2 \\
\hline & Gel coat sprayer & 511 & 24.7 & 3.6 \\
\hline & Gel coat sprayer & 603 & 30.1 & 2.5 \\
\hline & Infuser & 605 & 30.3 & 4.2 \\
\hline & Infuser & 620 & 31.0 & 2.7 \\
\hline & Team lead & 623 & 31.1 & 5.8 \\
\hline & Mold close/repairs & 425 & 32.3 & 6.0 \\
\hline & Closing and infusion & 462 & 23.1 & 4.3 \\
\hline & Repairs and gluing & 473 & 23.7 & 4.4 \\
\hline & Bushing winding & 506 & 25.3 & 12 \\
\hline \multicolumn{2}{|c|}{ NIOSH REL } & & & 50 \\
\hline \multirow{2}{*}{\multicolumn{2}{|c|}{$\begin{array}{l}\text { OSHA PEL } \\
\text { ACGIH }\end{array}$}} & & & 100 \\
\hline & & & & $20(14)$ \\
\hline
\end{tabular}

*Sample pump postcalibration $18 \%$ below preshift calibration flow rate, so concentration may not be an accurate estimate of exposure.

†Sample pump failed early in shift when employee was not spraying gel; replacement pump captured gel spraying exposure.

$\ddagger$ Sample pump failed an unknown amount of time after a periodic pump check 312 minutes into the shift.

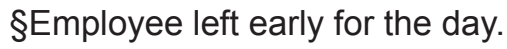


Table A2. Building 2 (premolding and postmolding) personal air sample results for styrene, June 11-13, 2013

\begin{tabular}{|c|c|c|c|c|}
\hline Date & Department - job/activity & $\begin{array}{l}\text { Sample } \\
\text { duration } \\
\text { (minutes) }\end{array}$ & $\begin{array}{l}\text { Total } \\
\text { volume } \\
\text { (liters) }\end{array}$ & $\begin{array}{l}\text { Concentration } \\
\quad(p p m)\end{array}$ \\
\hline \multirow{15}{*}{ June 11} & Finishing and assembly - lead & 585 & 28 & 4.5 \\
\hline & Finishing and assembly - assembler & 625 & 31.3 & 6.2 \\
\hline & Finishing and assembly - assembler & 668 & 33.4 & 9.1 \\
\hline & Finishing and assembly - painter & 606 & 29.4 & 7.0 \\
\hline & Finishing and assembly - painter & 569 & 28.1 & 8.2 \\
\hline & Web molding - lead & 617 & 30.9 & 2.2 \\
\hline & Blade cut and trim - outside & 627 & 31.4 & 23 \\
\hline & Blade cut and trim - outside & 474 & 23.7 & 8.1 \\
\hline & Blade cut and trim - outside & 564 & 28.2 & 3.8 \\
\hline & Blade cut and trim - attendant & 612 & 30.6 & 7.7 \\
\hline & Blade cut and trim - attendant & 591 & 29.6 & 13 \\
\hline & Blade cut and trim - inside & 591 & 29.6 & 6.9 \\
\hline & Blade cut and trim - inside & 547 & 27.4 & 36 \\
\hline & Blade cut and trim - inside & 376 & 18.8 & 54 \\
\hline & Safety platform layup & 546 & 27.3 & 13 \\
\hline \multirow[t]{13}{*}{ June 12} & Finishing and assembly - lead & 651 & 32.6 & 4.1 \\
\hline & $\begin{array}{c}\text { Finishing and assembly - } \\
\text { painter/sander }\end{array}$ & 686 & 34.3 & 8.9 \\
\hline & $\begin{array}{c}\text { Finishing and assembly - } \\
\text { painter/sander }\end{array}$ & 667 & 33.4 & 9.9 \\
\hline & Web molding - lead & 712 & 36 & 0.091 \\
\hline & Blade cut and trim - outside & 615 & 30.8 & 2.1 \\
\hline & Blade cut and trim - outside & 582 & 29.1 & 38 \\
\hline & Blade cut and trim - lead (outside) & 473 & 23.7 & 40 \\
\hline & Blade cut and trim - attendant & 581 & 29.1 & 9.7 \\
\hline & Blade cut and trim - attendant & 599 & 30 & 7.1 \\
\hline & Blade cut and trim - inside & 578 & 28.9 & $20^{*}$ \\
\hline & Blade cut and trim - inside & 523 & 23.1 & 56 \\
\hline & Blade cut and trim - inside & 424 & 21.2 & 51 \\
\hline & Safety platform layup & 547 & 27.4 & $20^{*}$ \\
\hline \multirow[t]{14}{*}{ June 13} & Finishing and assembly - lead & 627 & 31.4 & 3.9 \\
\hline & Finishing and assembly - assembler & 663 & 33.2 & 9.2 \\
\hline & $\begin{array}{c}\text { Finishing and assembly - } \\
\text { painter/sander }\end{array}$ & 595 & 28.7 & 1.3 \\
\hline & $\begin{array}{c}\text { Finishing and assembly - } \\
\text { painter/sander }\end{array}$ & 568 & 28.4 & 9.1 \\
\hline & Web molding - lead (infusion) & 653 & 32.7 & 10.1 \\
\hline & Blade cut and trim - outside & 450 & 22.5 & $20^{*}$ \\
\hline & Blade cut and trim - outside & 590 & 29.5 & $16^{*}$ \\
\hline & Blade cut and trim - outside & 403 & 20.2 & 5.9 \\
\hline & Blade cut and trim - attendant & 528 & 26.4 & 7.6 \\
\hline & Blade cut and trim - attendant & 554 & 27.7 & 7.5 \\
\hline & Blade cut and trim - inside & 468 & 23.4 & 30.1 \\
\hline & Blade cut and trim - inside & 466 & 23.3 & 66 \\
\hline & Blade cut and trim - inside & 489 & 24.5 & 26 \\
\hline & Safety platform layup & 530 & 26.3 & 11 \\
\hline \multirow{3}{*}{\multicolumn{2}{|c|}{$\begin{array}{l}\text { NIOSH REL } \\
\text { OSHA PEL } \\
\text { ACGIH TLV (10-hour shift-adjusted TLV) }\end{array}$}} & & & 50 \\
\hline & & & & 100 \\
\hline & & & & $20(14)$ \\
\hline
\end{tabular}

*Denotes employee worked 10-hour shift and exceeded the adjusted TLV. 
Table A3. Building 2 personal air sample results for total dust, June 11-13, 2013

\begin{tabular}{|c|c|c|c|c|}
\hline Date & Department - job/activity & $\begin{array}{c}\text { Sample } \\
\text { duration } \\
\text { (minutes) }\end{array}$ & $\begin{array}{c}\text { Total } \\
\text { volume } \\
\text { (liters) }\end{array}$ & $\begin{array}{l}\text { Concentration } \\
\left(\mathrm{mg} / \mathrm{m}^{3}\right)\end{array}$ \\
\hline \multirow[t]{10}{*}{ June 11} & Bushing winding & $261^{*}$ & 392 & 0.28 \\
\hline & Finishing and assembly - lead & 585 & 878 & 0.84 \\
\hline & Finishing and assembly - painter & 567 & 851 & 2.4 \\
\hline & Finishing and assembly - painter & 604 & 906 & 4.9 \\
\hline & Web cut and trim & 571 & 857 & 3.3 \\
\hline & Web cut and trim & 486 & 729 & 7.2 \\
\hline & Web cut and trim & 624 & 936 & 29 \\
\hline & Blade cut and trim - inside & 373 & 560 & 49 \\
\hline & $\begin{array}{l}\text { Blade cut and trim - } \\
\text { inside and outside }\end{array}$ & 386 & 579 & 4.9 \\
\hline & Blade cut and trim - outside & 616 & 905 & 39 \\
\hline \multirow{10}{*}{ June 12} & Bushing winding & 467 & 701 & 0.16 \\
\hline & Finishing and assembly - lead & 646 & 969 & 0.82 \\
\hline & $\begin{array}{c}\text { Finishing and assembly - } \\
\text { painter/sander }\end{array}$ & 682 & 1023 & $19 \dagger$ \\
\hline & $\begin{array}{l}\text { Finishing and assembly - } \\
\text { painter/sander }\end{array}$ & 640 & 960 & 4.3 \\
\hline & Web cut and trim & 381 & 572 & 9.1 \\
\hline & Web cut and trim & 510 & 765 & 3.6 \\
\hline & Blade cut and trim - inside & 403 & 605 & 38 \\
\hline & Blade cut and trim - inside & 420 & 630 & 77 \\
\hline & Blade cut and trim - inside & 515 & 773 & 90 \\
\hline & Blade cut and trim - inside & $282^{*}$ & 423 & 16 \\
\hline \multirow[t]{9}{*}{ June 13} & $\begin{array}{c}\text { Finishing and assembly - } \\
\text { painter/sander }\end{array}$ & 591 & 887 & 2.5 \\
\hline & $\begin{array}{c}\text { Finishing and assembly - } \\
\text { painter/sander }\end{array}$ & 564 & 846 & 3.9 \\
\hline & Finishing and assembly - lead & 624 & 936 & 0.91 \\
\hline & Web cut and trim & 515 & 773 & 52 \\
\hline & Web cut and trim & 535 & 803 & 26 \\
\hline & Blade cut and trim - inside & 463 & 695 & 62 \\
\hline & Blade cut and trim - inside & 452 & 678 & 44 \\
\hline & Blade cut and trim - outside & 399 & 599 & 13 \\
\hline & Blade cut and trim - outside & 586 & 879 & 12 \\
\hline \multicolumn{2}{|c|}{ NIOSH REL } & & & - \\
\hline \multicolumn{2}{|c|}{ OSHA PEL } & & & 15 \\
\hline \multicolumn{2}{|c|}{ ACGIH guideline } & & & 10 \\
\hline
\end{tabular}

${ }^{*}$ A sampling pump faulted intermittently throughout the shift but post-calibration was no more than $5 \%$ different from preshift pump calibration flow rate; therefore, concentration listed here was calculated on the basis of the sampling time listed in this table.

†Local exhaust ventilation hose on sander was clogged. 


\section{Appendix B: Questionnaire}

ID:

HETA 2013-0056

Interviewer:

Interview Date:

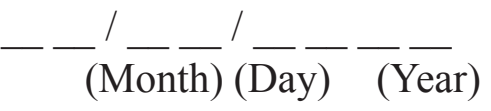

Section I: Identification and Demographic Information

Name:

(Last Name)

(First Name)

$\overline{(\mathrm{M} . \mathrm{I}}$ )

Address:

(Number, Street, and/or Rural Route)

(City)

$\overline{(\text { State) }} \overline{(\text { Zip Code })}$

Primary Telephone Number:

${ }^{-}{ }^{-}{ }^{-} \_[\text {] Home [ ] Cell }$

If you were to move, is there someone who would know how to contact you?

Name:

(Last Name)

(First Name)

$\overline{(\text { M.I. })}$

Relationship to you:

Address:

(Number, Street, and/or Rural Route)

(City)

$\overline{(\text { State) }} \overline{(\text { Zip Code })}$

Primary Telephone Number:

$(+\ldots)$ - __ [ ] Home [ ] Cell

1. Date of Birth:

$\overline{\text { (Month) (Day) }}{ }^{\prime} \overline{\text { (Year) }}-$

2. Sex:

1.___ Male $0 . \_$Female

3. Are you Spanish, Hispanic or Latino?

1.___ Yes $0 . \_$No 
4. Select one or more of the following categories to describe your race:

1. American Indian or Alaska Native

2. Asian

3. African-American or Black

4. Native Hawaiian or Other Pacific Islander

5. White

\section{Section II: Health Information}

I'm going to ask you some questions about your health. The answer to many of these questions will be "Yes" or "No." If you are in doubt about whether to answer "Yes" or "No," then please answer "No."

5. Are you troubled by shortness of breath when hurrying on

level ground or walking up a slight hill?

1.___ Yes 0.

\section{If YES:}

5.1. In what month and year did this shortness of breath first begin?

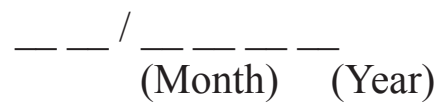

5.2. When you are away from this plant on days off or on vacation, is this shortness of breath

1.__ Same

2._Worse

3. Better

5.3. Do you get short of breath walking with other people of your own age on level ground? $\quad 1 . \_$Yes $0 . \_$No

5.4. Do you ever have to stop for breath when walking at your own pace on level ground? $\quad 1$ ___ Yes $0 . \ldots$ No

6. Do you usually have a cough?

1.__ Yes $0 . \_$No

(Count a cough with first smoke or on first going out of doors. Exclude clearing of throat.)

\section{IF YES:}

6.1. In what month and year did this cough first begin?

6.2. Do you usually cough on most days for 3 consecutive months or more during the year?

6.3. When you are away from this plant on days off or on vacation, is your cough:

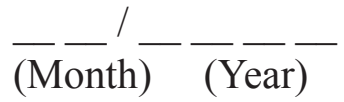

1.___ Yes 0.

1.__ Same

2._Worse

3. Better 
6.4. Is there anything at work that causes or aggravates this cough?

1.___ Yes $0 . \_$No

IF YES:

6.4.1 What do you think causes or aggravates this cough?

7. Do you usually bring up phlegm from your chest?

1.__ Yes 0. No (Count phlegm with first smoke or on first going out of doors. Exclude phlegm from the nose. Count swallowed phlegm.)

IF YES:

7.1. In what month and year did this phlegm first begin?

$$
\overline{\text { (Month) }}+\frac{1}{\text { (Year) }}
$$

7.2. Do you bring up phlegm on most days for 3 consecutive months or more during the year?

1._ Yes

$0 . \quad$ No

8. Have you had wheezing or whistling in your chest at any time in the last 12 months? 1.___ Yes 0.

IF YES:

8.1. In what month and year did this wheezing or whistling first begin?

$\overline{\text { (Month) }}-\frac{1}{\text { (Year) }}$

8.2. When you are away from this plant on days off or on vacation, is this wheezing or whistling:

1. Same

2._Worse

3._B Better

8.3. Is there anything at work that causes or aggravates this wheezing or whistling? $\quad 1 . \ldots$ Yes $0 . \_$No

9. Have you woken up with a feeling of tightness in your chest at any time in the last 12 months?

1 Yes $0 . \quad$ No 
IF YES:

9.1. In what month and year did this chest tightness first begin?

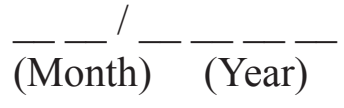

9.2. When you are away from this plant on days off or on vacation, is this chest tightness :

1.___ Same

2._ Worse

3._Better

10. Have you had an attack of asthma in the last 12 months? 1.___ Yes $0 . \_$No

\section{IF YES:}

10.1. In what month and year did these attacks of asthma first begin?

$$
\overline{\text { (Month) }} \overline{\text { (Year) }}
$$

10.2. When you are away from this plant on days off or on vacation, are these attacks of asthma: 1.

2._B Worse

10.3. Is there anything at work that causes or aggravates these attacks of asthma?

1. Yes 0. IF YES:

10.3.1. What do you think causes or aggravates these attacks of asthma?

11. Are you currently taking any medicine (including inhalers, aerosols or tablets) for asthma?

1.___ Yes $0 . \_$No

IF YES:

11.1. In what month and year did you first begin using medicine for asthma?

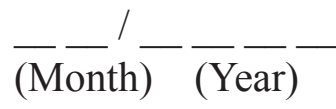

11.2. When you are away from this plant on days off or on vacation, do you take the medicine for asthma:

1. The Same

2.__ More often

3.___Less often 
12. In the last 12 months, have you had any episodes of stuffy, itchy, or runny nose?
1.
Yes 0. No

IF YES:

12.1. When you are away from this plant on days off or on vacation, are these nose symptoms 1 .
1.___ Same
2. Worse
3. Better

13. In the last 12 months, have you had any episodes of watery,

itchy eyes?

1.__ Yes 0.

IF YES:

13.1. When you are away from this plant on days off or on vacation, are these eye symptoms

1.___ Same
2._ Worse
3._ Better

14. In the last 12 months, have you had any skin rash or skin problems?

1.___ Yes 0.

IF YES:

14.1. When you are away from this plant on days off or on vacation, are these skin problems
1.__ Same
2. Worse
3. Better

14.2. Which of the following describes your skin problem? (check all that apply)
i. red, inflamed skin
1.__ Yes $0 . \quad$ No
ii. hives
iii. dry or itchy skin
1.__ Yes $0 . \quad$ No
iv. peeling skin
1. Yes 0 . No
1. Yes 0 . No

14.3. Which of the following areas of your body were affected by your skin problem?

(check all that apply)

i. your face

ii. your neck

1.___ Yes 0.

iii. your arms

1. Yes $0 . \quad$ No

iv. your hands

1.___ Yes $0 . \quad$ No

v. other areas?

1.__ Yes $0 . \quad$ No

1.___ Yes $0 . \_$No

14.4 Is there something at work that causes or aggravates these skin problems?

1. Yes 0 No 


\section{IF YES:}

14.4.1 What do you think causes or aggravates these skin problems?

15. Have you ever been told by a physician that you had any of the following conditions?

\begin{tabular}{|c|c|c|c|}
\hline Conditions & Told by a phys & ician you had? & Month and Year \\
\hline 1. Hay fever or nasal allergies & 1. Yes __ & $0 . \mathrm{No}$ & \\
\hline $\begin{array}{l}\text { 2. Eczema, dermatitis, or } \\
\text { skin allergy }\end{array}$ & 1. Yes __ & 0. No & \\
\hline 3. Chronic bronchitis & 1. Yes & 0. No & \\
\hline 4. Emphysema & 1. Yes & 0. No & \\
\hline 5. Pneumonia & 1. Yes & $0 . \mathrm{No}$ & \\
\hline $\begin{array}{l}\text { 6. Chronic obstructive pulmonary } \\
\text { disease (COPD) }\end{array}$ & 1. Yes & $0 . \mathrm{No}$ & \\
\hline 7. Asthma & 1. Yes __ & 0. No & \\
\hline $\begin{array}{l}\text { 7.1. IF YES: } \\
\text { Do you still have asthma? }\end{array}$ & 1. Yes & $0 . \mathrm{No}_{-}$ & \\
\hline
\end{tabular}

16. Have you ever been told by a physician that you had any other respiratory condition? $\quad 1 . \_$Yes $0 . \_$No

IF YES:

16.1. What was the diagnosis?

16.2. In what month and year were you first given this diagnosis?

$\overline{\text { (Month) }} \overline{\text { (Year) }}$ 
17. Have you ever been told by a physician that you had any of the following conditions?

\begin{tabular}{|c|c|c|}
\hline Conditions & Told by a physician you had & $\begin{array}{l}\text { Month and Year } \\
\text { of first diagnosis? }\end{array}$ \\
\hline 1. Diabetes & 1. Yes _ $0 . \mathrm{No}_{-}$ & \\
\hline 2. Glaucoma & 1. Yes__ $0 . \mathrm{No}$ & \\
\hline 3. Macular degeneration & 1. Yes $\quad 0$. No & \\
\hline 4. Cataract(s) & 1. Yes $\quad 0 . \mathrm{No}$ & \\
\hline 5. Amblyopia (lazy eye) & - $0 . \mathrm{No}_{2}$ & \\
\hline 6. Color blindness & 1. Yes & \\
\hline
\end{tabular}

18. Have you had eye surgery such as LASIK surgery, cataract surgery, retinal surgery, any other eye surgery? 1.__ Yes $0 . \ldots$ No

IF YES:

18.1. Please describe your eye surgery: 
Section III. Work Information

19. I'm now going to ask you to list all of the jobs that you have had while working at (employer name).

We will start with your current job and work back through time. If you had gaps in your employment at (employer name), I am interested in knowing that too.

\begin{tabular}{|l|c|l|l|l|}
\hline $\begin{array}{c}\text { Job } \\
\text { Number }\end{array}$ & Department & $\begin{array}{c}\text { Job } \\
\text { Title }\end{array}$ & $\begin{array}{c}\text { Start Date } \\
\text { (MM/YYY) }\end{array}$ & $\begin{array}{c}\text { End Date } \\
\text { (MM/YYY) }\end{array}$ \\
\hline & $\begin{array}{c}\text { Drop Down menus } \\
\text { populated with lists }\end{array}$ & & & \\
\hline & & & & \\
\hline & & & & \\
\hline & & & & \\
\hline & & & & \\
\hline & & & & \\
\hline & & & & \\
\hline & & & & \\
\hline & & & & \\
\hline & & & & \\
\hline & & & & \\
\hline & & & & \\
\hline & & & & \\
\hline & & & & \\
\hline & & & & \\
\hline
\end{tabular}


20. I now have some questions about tasks that you perform as part of your current job.

\begin{tabular}{|c|c|}
\hline Tasks & Current job \\
\hline In your current job do you spray gel-coat? & 1. Yes _ 0. No \\
\hline In your current job do you operate the gel-coat machine? & 1. Yes \\
\hline $\begin{array}{l}\text { In your current job do you remove the plastic from the wind- } \\
\text { blade after the resin hardens? }\end{array}$ & 1. Yes __ 0 . No \\
\hline $\begin{array}{l}\text { In your current job do you perform grinding before the blade } \\
\text { is closed? }\end{array}$ & 1. Yes __ 0 . No \\
\hline $\begin{array}{l}\text { In your current job do you perform grinding / sanding inside } \\
\text { the blade? }\end{array}$ & 1. Yes __ 0 . No \\
\hline $\begin{array}{l}\text { In your current job do you perform grinding / sanding the } \\
\text { blade outside? }\end{array}$ & 1. Yes __ 0 . No \\
\hline $\begin{array}{l}\text { In your current job do you perform layups on the inside of the } \\
\text { blade? }\end{array}$ & 1. Yes __ 0 . No \\
\hline $\begin{array}{l}\text { In your current job do you perform layups on the outside of } \\
\text { the blade? }\end{array}$ & 1. Yes _ 0 . No \\
\hline In your current job do you perform safety platform layups? & 1. Yes \\
\hline In your current job do you balance the blades? & 1. Yes _ 0. No \\
\hline In your current job do you paint the blades? & 1. Yes \\
\hline In your current job do you grind / sand webbing? & 1. Yes 0. No \\
\hline In your current job do you perform kitting? & 1. Yes _ 0. No \\
\hline In your current job do you wind bushings? & 1. Yes 0. No \\
\hline In your current job do you glue bushings? & 1. Yes_ 0. No \\
\hline In your current job do you infuse resin for webs? & 1. Yes _ 0. No \\
\hline In your current job do you infuse resin for the blades? & 1. Yes _ 0. No \\
\hline
\end{tabular}


20.1 For each Yes ask the following:

\begin{tabular}{|c|c|c|c|}
\hline $\begin{array}{l}\text { (a) Have you } \\
\text { performed this } \\
\text { task on your } \\
\text { shift so far } \\
\text { today? }\end{array}$ & $\begin{array}{l}\text { (b) Do you ex- } \\
\text { pect to perform } \\
\text { this task on your } \\
\text { shift today? }\end{array}$ & $\begin{array}{l}\text { (c) While doing this task which } \\
\text { type(s) of respirator or mask } \\
\text { do you wear? }\end{array}$ & $\begin{array}{l}\text { (d) Do you wear any of the } \\
\text { following protective gear } \\
\text { while performing this task? }\end{array}$ \\
\hline Yes. __ No. _ & Yes. _ No. _ & $\begin{array}{l}\text { 1.__ Dust mask } \\
\text { 2.__ Disposable respirator } \\
\text { (N95) } \\
\text { 3.__ Half-face respirator } \\
\text { 4. _ Full-face respirator } \\
\text { 5.__ loose fitting PAPR } \\
\text { 6. _ supplied air } \\
\text { 7.__ none }\end{array}$ & $\begin{array}{l}\text { 1.__ white Micromax }{ }^{\circledR} \\
\text { coveralls } \\
\text { 2.__ white Micromax } \\
\text { sleeves } \\
\text { 3.__ white Micromax coat } \\
\text { 4.__ yellow "chemical suit" } \\
\text { 5.__ leather gloves } \\
\text { 6.__ nitrile gloves } \\
\text { 7._ cloth gloves } \\
\text { 8._ other gloves } \\
\text { 9.__ goggles } \\
\text { 10. none }\end{array}$ \\
\hline
\end{tabular}

21. Prior to your work at (employer name), have you ever worked in the following industries?

21.1 If yes, for about how many years did you work in this industry?

\begin{tabular}{|l|c|c|}
\hline & Ever worked? & \# years \\
\hline Auto-body industry & 1. Yes_0. No & \\
\hline Reinforced plastics & 1. Yes_0. No & \\
\hline $\begin{array}{l}\text { In an industry with } \\
\text { fiberglass }\end{array}$ & $\ldots$ 1. Yes_0. No & \\
\hline
\end{tabular}


Section V: Tobacco Use Information

I'm now going to ask you a few questions about tobacco use.

22. Have you ever smoked cigarettes?

1. Yes 0. No

(NO if less than 20 packs of cigarettes in a lifetime or less than 1 cigarette a day for 1 year.)

IF YES:

22.1 How old were you when you first started smoking regularly?

Years old

22.2 Over the entire time that you have smoked, what is the average number of cigarettes you smoked per day?

Cigarettes/day

22.3 Do you still smoke cigarettes?

1.__ Yes 0.

IF NO:

22.3.1 How old were you when you stopped smoking cigarettes regularly?

Years old

Thank you for participating in this survey! 


\section{Appendix C: Occupational Exposure Limits and Health Effects}

NIOSH investigators refer to mandatory (legally enforceable) and recommended OELs for chemical, physical, and biological agents when evaluating workplace hazards. OELs have been developed by federal agencies and safety and health organizations to prevent adverse health effects from workplace exposures. Generally, OELs suggest levels of exposure that most employees may be exposed to for up to 10 hours per day, 40 hours per week, for a working lifetime, without experiencing adverse health effects. However, not all employees will be protected if their exposures are maintained below these levels. Some may have adverse health effects because of individual susceptibility, a pre-existing medical condition, or a hypersensitivity (allergy). In addition, some hazardous substances act in combination with other exposures, with the general environment, or with medications or personal habits of the employee to produce adverse health effects. Most OELs address airborne exposures, but some substances can be absorbed directly through the skin and mucous membranes.

Most OELs are expressed as a time-weighted average (TWA) exposure. A TWA refers to the average exposure during a normal 8- to 10-hour workday. Some chemical substances and physical agents have recommended short-term exposure limit or ceiling values. Unless otherwise noted, the short term exposure is a 15-minute TWA exposure. It should not be exceeded at any time during a workday. The ceiling limit should not be exceeded at any time.

In the United States, OELs have been established by federal agencies, professional organizations, state and local governments, and other entities. Some OELs are legally enforceable limits; others are recommendations.

- The U.S. Department of Labor OSHA PELs (29 CFR 1910 [general industry]; 29 CFR 1926 [construction industry]; and 29 CFR 1917 [maritime industry]) are legal limits. These limits are enforceable in workplaces covered under the Occupational Safety and Health Act of 1970.

- NIOSH RELs are recommendations based on a critical review of the scientific and technical information and the adequacy of methods to identify and control the hazard. NIOSH RELs are published in the NIOSH Pocket Guide to Chemical Hazards [NIOSH 2010]. NIOSH also recommends risk management practices (e.g., engineering controls, safe work practices, employee education/training, PPE, and exposure and medical monitoring) to minimize the risk of exposure and adverse health effects.

- Other OELs commonly used and cited in the United States include the TLVs, which are recommended by ACGIH, a professional organization, and the workplace environmental exposure limits (WEELs), which are recommended by the American Industrial Hygiene Association, another professional organization. The TLVs and WEELs are developed by committee members of these associations from a review of the published, peer-reviewed literature. These OELs are not consensus standards. TLVs 
are considered voluntary exposure guidelines for use by industrial hygienists and others trained in this discipline "to assist in the control of health hazards" [ACGIH 2016a].

WEELs have been established for some chemicals "when no other legal or authoritative limits exist" [AIHA 2016].

Outside the United States, OELs have been established by various agencies and organizations and include legal and recommended limits. The Institut für Arbeitsschutz der Deutschen Gesetzlichen Unfallversicherung (Institute for Occupational Safety and Health of the German Social Accident Insurance) maintains a database of international OELs from European Union member states, Canada (Québec), Japan, Switzerland, and the United States. The database, available at http://www.dguv.de/ifa/GESTIS/GESTIS-Internationale-Grenzwerte-fürchemische-Substanzen-limit-values-for-chemical-agents/index-2.jsp, contains international limits for more than 2,000 hazardous substances and is updated periodically.

OSHA requires an employer to furnish employees a place of employment free from recognized hazards that cause or are likely to cause death or serious physical harm [Occupational Safety and Health Act of 1970 (Public Law 91-596, sec. 5(a)(1))]. This is true in the absence of a specific OEL. It also is important to keep in mind that OELs may not reflect current health-based information.

When multiple OELs exist for a substance or agent, NIOSH investigators generally encourage employers to use the lowest OEL when making risk assessment and risk management decisions. NIOSH investigators also encourage use of the hierarchy of controls approach to eliminate or minimize workplace hazards. This includes, in order of preference, the use of (1) substitution or elimination of the hazardous agent, (2) engineering controls (e.g., local exhaust ventilation, process enclosure, dilution ventilation), (3) administrative controls (e.g., limiting time of exposure, employee training, work practice changes, medical surveillance), and (4) PPE (e.g., respiratory protection, gloves, eye protection, hearing protection). Control banding, a qualitative risk assessment and risk management tool, is a complementary approach to protecting employee health. Control banding focuses on how broad categories of risk should be managed. Information on control banding is available at http://www.cdc.gov/niosh/topics/ctrlbanding/. This approach can be applied in situations where OELs have not been established or can be used to supplement existing OELs.

\section{Styrene}

Styrene is a volatile, colorless to yellow, oily liquid with a sweet, floral odor [NIOSH 2010]. The use of styrene in industry includes manufacturing polystyrene plastics, protective coatings, copolymer resins with acrylonitrile and butadiene, and using it as a chemical intermediary [ACGIH 2016b]. Exposure to styrene has been reported to cause eye and respiratory irritation in addition to central nervous system effects. Humans have reported symptoms such as headaches, dizziness, fatigue, and nausea when exposed to styrene concentrations between 50 and 100 ppm and above [ACGIH 2016a].

The OSHA PEL for styrene is 100 ppm for an 8-hour TWA exposure [29 CFR 1910.1000] and $200 \mathrm{ppm}$ as a ceiling limit. The NIOSH REL for styrene is $50 \mathrm{ppm}$ for up to a 10-hour 
TWA exposure (during a 40-hour workweek) and $100 \mathrm{ppm}$ for a short-term exposure limit [NIOSH 2010]. ACGIH recommends an 8-hour TWA TLV of 20 ppm, a short-term exposure limit of $40 \mathrm{ppm}$, and assigns it an A4 designation (not classifiable as a human carcinogen) [ACGIH 2016a]. These values are intended to minimize the potential for central and peripheral nervous system effects and for mucous membrane and respiratory tract irritation. The central nervous system effects that have been reported include deficits in color vision and high frequency hearing [ACGIH 2016a].

\section{Particulates Not Otherwise Regulated or Specified}

Particulates not otherwise regulated or specified are typically characterized as an organic, inorganic, or mineral dust that does not have its own specific occupational health exposure criterion. Nuisance dusts have generally been described as "inert" or not producing a toxic effect or disease. However, there is the potential for respiratory tract, eye, and skin irritation depending upon the individual dust characteristics (particle size, composition, etc.), and concentration.

The OSHA PELs for particulates not otherwise regulated are $15 \mathrm{mg} / \mathrm{m}^{3}$ for total dust and $5 \mathrm{mg} / \mathrm{m}^{3}$ for respirable dust [29 CFR 1910.1000]. ACGIH has not developed a TLV for dust but has established guidelines for particles (insoluble or poorly soluble) not otherwise specified. ACGIH recommends that respirable particles not otherwise specified be kept below $3 \mathrm{mg} / \mathrm{m}^{3}$, and inhalable particles not otherwise specified be kept below $10 \mathrm{mg} / \mathrm{m}^{3}$ [ACGIH 2016a]. 


\section{References}

ACGIH [2016a]. 2016 TLVs ${ }^{\circledR}$ and BEIs ${ }^{\circledR}$ : threshold limit values for chemical substances and physical agents and biological exposure indices. Cincinnati, OH: American Conference of Governmental Industrial Hygienists.

ACGIH [2016b]. Documentation of the threshold limit values and biological exposure indices, 7th edition. Cincinnati, OH: American Conference of Governmental Industrial Hygienists.

AIHA [2016]. AIHA 2016 emergency response planning guidelines (ERPG) \& workplace environmental exposure levels (WEEL) handbook. Fairfax, VA: American Industrial Hygiene Association.

Alwis KU, Blount BC, Britt AS, Patel D, Ashley DL [2012]. Simultaneous analysis of 20 urinary VOC metabolites using ultra high performance liquid chromatography coupled with electrospray ionization tandem mass spectrometry. Analytica Chimica Acta 750:152-160.

Birch J [2012]. Worldwide prevalence of red-green color deficiency. J Optic Soc Amer 29(3):313-320.

Brief R, Scala R [1975]. Occupational exposure limits for novel work schedules. Am Ind Hyg Assoc J 36(6):467-469.

Burgel PR [2011]. The role of small airways in obstructive airway disease. Eur Respir Rev 20(119):23-33.

Campagna D, Mergler D, Huel G, Belanger S, Truchon G, Ostiguy C, Drolet D [1995]. Visual dysfunction among styrene exposed workers. Scand J Work Environ Health 21(5):382-390.

Castillo L, Baldwin M, Sassine M, Mergler D [2001]. Cumulative exposure to styrene and visual functions. Am J Ind Med 39(4):351-360.

Chen CH, Tsai PJ, Wang WC, Pan CH, Ho JJ, Guo YL [2013]. Obliterative bronchiolitis in workers laying up fiberglass-reinforced plastic with polyester resin and methylethyl ketone peroxide catalyst. Occup Environ Med 70(9):675-676.

Code of Federal Regulations. Washington, DC: U.S. Government Printing Office, Office of the Federal Register.

Collins JJ, Bodner KM, Bus JS [2013]. Cancer mortality of workers exposed to styrene in the U.S. reinforced plastics and composite industry. Epidemiology 24(2):195-203.

Cornell Statistical Consulting Unit [2012]. StatNews \#83: interpreting coefficients in regression with log transformed variables. https://www.cscu.cornell.edu/news/statnews/ stnews83.pdf.

Cullinan P, McGavin CR, Kreiss K, Nicholson AG, Maher TM, Howell T, Banks J, Newman Taylor AJ, Chen CH, Tsai PJ, Shih TS, Burge PS [2013]. Obliterative bronchiolitis in fibreglass workers: a new occupational disease? Occup Environ Med 70(5):357-359. 
Cummings KJ, McCague AB, Kreiss K [2014]. Nonmalignant respiratory disease mortality in styrene-exposed workers. Epidemiology 25(1):160-161.

Department of Health and Human Services (DHHS) [1996]. National Center for Health Statistics. Third National Health and Nutrition Examination Survey, 1988-1994, NHANES III Adult and Examination Data Files (CD-ROM). Public Use Data File Documentation Number 76200. Hyattsville, MD: Centers for Disease Control and Prevention.

Doney B, Hnizdo E, Dillon CF, Paulose-Ram R, Tilert T, Wolz M, Beeckman-Wagner LA [2014]. Prevalence of airflow obstruction in U.S. adults aged 40-79 years: NHANES data 1988-1994 and 2007-2010. COPD 12(4):355-365, http://dx.doi.org/10.3109/15412555.2014.948998.

Dweik RA, Boggs PB, Erzurum SC, Irvin CG, Leigh MW, Lundberg JO, Olin A, Plummer AL, Taylor DR [2011]. An official ATS clinical practice guideline: interpretation of exhaled nitric oxide levels (FeNO) for clinical applications. Am J Respir Crit Care Med 184(5):602-615.

Eguchi R, Kishi R, Harabuchi I, Yuasa J, Arata Y, Katakura Y, Miyake H [1992]. Impaired colour discrimination among workers exposed to styrene: relevance of a urinary metabolite. Occup Environ Med 52(8):534-538.

Ferris BG [1978]. Epidemiology standardization project (American Thoracic Society). Am Rev Respir Dis 118(6 Pt 2):1-120.

Fox DA, Boyes WK [2013]. Toxic responses of the ocular and visual system. In: Klassen CD, ed. Casarett \& Doull's toxicology, the basic science of poisons. 8th rev. ed. New York: McGraw-Hill Education, pp. 767-798.

Geller AM [2001]. A table of color distance scores for quantitative scoring of the Lanthony Desaturate color vision test. Neurotoxicol Teratol 23(3):265-267.

Geller AM, Hudnell HK [1997]. Critical issues in the use and analysis of the Lanthony Desaturate color vision test. Neurotoxicol Teratol 19(6):455-465.

Ginsburg AP [1993]. Functional acuity contrast test F.A.C.T.1 instructions for use. Chicago, IL: Stereo Optical Company, Inc.

Grassi M, Rezzani C, Biino G, Marinoni A [2003]. Asthma-like symptoms assessment through ECRHS screening questionnaire scoring. J Clin Epidemiol 56(3):238-247.

Hammond D, Garcia A, Feng HA [2011]. Occupational exposures to styrene vapor in a manufacturing plant for fiber-reinforced composite wind turbine blades. Ann Occup Hyg 55(6):591-600.

Hankinson JL, Odencrantz JR, Fedan KB [1999]. Spirometric reference values from a sample of the general U.S. population. Am J Respir Crit Care Med 159(1):179-187.

Helal SF, Elshafy WS [2012]. Health hazards among workers in plastic industry. Toxicol Ind Health 29(9):812-819. 
Iregen A, Johnson A, Nylen P [2004]. Low level styrene exposure and color vision in Swedish styrene workers. Environ Toxicol Pharmacol 19(3):511-516.

Kalloniatis M, Luu C [2007]. Color perception. In: Kold H, Nelson R, Fernandez E, Jones B, editors. Webvision: The organization of the retina and visual system. http://webvision.med. utah.edu/book/part-viii- gabac-receptors/color-perception.

Kishi R, Eguchi T, Yuasa J, Katakura Y, Arata Y, Harabuchi I, Kawai T, Masuchi A [2001]. Effects of low-level occupational exposure to styrene on color vision: dose relation with a urinary metabolite. Environ Res 85(1):25-30.

Manini P, Andreoli R, Poli D, De Palma G, Mutti A, Niesse W [2002]. Liquid chromatography/electrospray tandem mass spectrometry characterization of sturene metabolism in man and in rat. Rapid Commun Mass Spectrom 16(24):2239-2248.

Miller MR, Hankinson J, Brusasco V, Burgos F, Casaburi R, Coates A, Crapo R, Enright P, van der Grinten CP, Gustafsson P, Jensen R, Johnson DC, MacIntyre N, McKay R, Navajas D, Pedersen OF, Pellegrino R, Viegi G, Wanger J [2005]. Standardisation of spirometry. Eur Respir J 26(2):319-338.

Moscato G, Biscaldi G, Cottica D, Pugliese F, Candura S, Candura F [1987]. Occupational asthma due to styrene: two case reports. J Occup Med 29(12):957-960.

NIOSH [2010]. NIOSH pocket guide to chemical hazards. Cincinnati, OH: U.S. Department of Health and Human Services, Centers for Disease Control and Prevention, National Institute for Occupational Safety and Health, DHHS (NIOSH) Publication No. 2010-168c, http://www.cdc.gov/niosh/npg/.

NIOSH [2013]. Software longitudinal data analysis (SPIROLA) software. http://www.cdc. gov/niosh/topics/spirometry/spirola-software.html.

NIOSH [2016]. NIOSH manual of analytical methods (NMAM®). 4th ed. Schlecht PC, O'Connor PF, eds. Cincinnati, OH: U.S. Department of Health and Human Services, Centers for Disease Control and Prevention, National Institute for Occupational Safety and Health, DHHS (NIOSH) Publication 94-113 (August 1994); 1st Supplement Publication 96-135, 2nd Supplement Publication 98-119; 3rd Supplement 2003-154, http://www.cdc.gov/niosh/ docs/2003-154/.

Pala G, Pignatti P, Moscato G [2011]. The use of fractional exhaled nitric oxide in investigation of work-related cough in a hairdresser. Am J Ind Med 54(7):565-568.

Pellegrino R, Viegi G, Brusasco V, Crapo RO, Burgos F, Casaburi R, Coates A, van der Grinten CP, Gustafsson P, Hankinson J, Jensen R, Johnson DC, MacIntyre N, McKay R, Miller MR, Navajas D, Pedersen OF, Wanger J [2005]. Interpretative strategies for lung function tests. Eur Respir J 26(5):948-968.

Quirce S, Lemiere C, de Blay F, del Pozo V, Gerth Van Wijk R, Maestrelli P, Pauli G, Pignatti P, Raulf-Heimsoth M, Sastre J, Storaas T, Moscato G [2012]. Noninvasive methods for assessment of airway inflammation in occupational settings. Allergy 65(4):445-458. 
Redlich CA, Tarlo SM, Hankinson JL, Townsend MC, Eschenbacher WL, Von Essen SG, Sigsgaard T, Weissman DN [2014]. Official American Thoracic Society technical standards: spirometry in the occupational setting. Am J Respir Crit Care Med 189(8):983-993.

Seeber A, Bruckner T, Triebig G [2009]. Occupational styrene exposure, color vision, and contrast sensitivity: a cohort study with repeated measurements. Int Arch Occup Environ Health 82(6):757-770.

Torok B [2014]. Web-based scoring software for the Farnswork-Munsell 100-hue, Roth 28hue, Farnsworth D-15, and the Lanthony D-15 desaturated arrangement tests. http://www. torok.info/colorvision/dir for use.htm.

Tseliou E, Bessa V, Hillas G, Delimpoura V, Papadaki G, Roussos C, Papiris S, Bakakos $\mathrm{P}$, Loukides S [2010]. Exhaled nitric oxide and exhaled breath condensate $\mathrm{pH}$ in severe refractory asthma. Chest 138(1):107-113.

Triebig G, Stark T, Ihrig A, Dietz M [2001]. Intervention study on acquired color vision deficiency in styrene-exposed workers. J Occup Environ Med 43(5):494-500.

Wilson HK, Robertson SM, Waldron HA, Gompertz D [1983]. Effect of alcohol on the kinectics of mendelic acid excretion in volunteers exposed to styrene vapour. Brit J Ind Med $40(1): 75-80$. 
Keywords: North American Industry Classification System 326199 (All Other Plastics Manufacturing), North Dakota, styrene, dust, visual contrast, respiratory, green energy, fiberglass, resin, color blindness 


\section{This page left intentionally blank}


The Health Hazard Evaluation Program investigates possible health hazards in the workplace under the authority of the Occupational Safety and Health Act of 1970 (29 U.S.C. § 669(a) (6)). The Health Hazard Evaluation Program also provides, upon request, technical assistance to federal, state, and local agencies to investigate occupational health hazards and to prevent occupational disease or injury. Regulations guiding the Program can be found in Title 42, Code of Federal Regulations, Part 85; Requests for Health Hazard Evaluations (42 CFR Part 85).

\section{Disclaimer}

The recommendations in this report are made on the basis of the findings at the workplace evaluated and may not be applicable to other workplaces.

Mention of any company or product in this report does not constitute endorsement by NIOSH.

Citations to Web sites external to NIOSH do not constitute NIOSH endorsement of the sponsoring organizations or their programs or products. NIOSH is not responsible for the content of these Web sites. All Web addresses referenced in this document were accessible as of the publication date.

\section{Acknowledgments}

Analytical Support: Bureau Veritas North America, National Center for Environmental Health Desktop Publisher: Shawna Watts

Editor: Ellen Galloway

Industrial Hygiene and Engineering Field Assistance: Karl Feldmann, Emily Lee, Duane Hammond Logistics: Donnie Booher and Karl Feldmann

Medical Field Assistance: Nina Ahmad, Jenna Armstrong, Mike Beaty, Randy Boylstein, Kim Brinker, Nicole Edwards, Diana Freeland, Candice Johnson, Kay Kreiss, Brent Lawrence, Ryan Lebouf, Cammie Menendez, Ken Quinto, Avima Ruder, Celeste Russell, Mary Siegel, Dave Spainhour, Marcia Stanton, Brian Tift, Joe Woodring Statistical Support: Jean Cox-Ganser, Nicole Edwards

\section{Availability of Report}

Copies of this report have been sent to the employer and employees at the facility. The state and local health department and the Occupational Safety and Health Administration Regional Office have also received a copy. This report is not copyrighted and may be freely reproduced.

\section{Recommended citation for this report:}

NIOSH [2016]. Evaluation of styrene and dust exposures and health effects during fiberglass-reinforced wind turbine blade manufacturing. By Harney JM, McCague A-B, Cummings KJ, Cox-Ganser J. Cincinnati, OH: U.S. Department of Health and Human Services, Centers for Disease Control and Prevention, National Institute for Occupational Safety and Health, Health Hazard Evaluation Report 2013-0056-3256, http://www.cdc.gov/niosh/hhe/reports/pdfs/2013-0056-3256.pdf. 
Delivering on the Nation's promise:

Safety and health at work for all people through research and prevention

To receive NIOSH documents or more information about occupational safety and health topics, please contact NIOSH:

Telephone: 1-800-CDC-INFO (1-800-232-4636)

TTY: 1-888-232-6348

CDC INFO: www.cdc.gov/info

or visit the NIOSH Web site at www.cdc.gov/niosh

For a monthly update on news at $\mathrm{NIOSH}$, subscribe to $\mathrm{NIOSH}$ eNews by visiting www.cdc.gov/niosh/eNews. 